\title{
Chemically triggered coalescence and reactivity of droplet fibers
}

Jing Zhao, ${ }^{+}$Zehao Pan, ${ }^{\ddagger}$ Deborah Snyder, ${ }^{+}$Howard A. Stone ${ }^{\ddagger}$ and Todd Emrick ${ }^{*}+$

+Polymer Science \& Engineering Department, University of Massachusetts, Amherst, MA, 01003.

$\ddagger$ Department of Mechanical and Aerospace Engineering, Princeton University, Princeton, NJ 08544 USA.

\section{Table of Contents}

\section{S.1 Experimental Section}

\section{S.2 Supporting Figures and Movie}

\section{S.3 Supporting References}

\section{S.1 Experimental Section}

Materials. The following chemicals were purchased from Sigma-Aldrich: acetonitrile (anhydrous, 99.8\%), 4,4'-azobis(4-cyanovaleric acid) (98\%), 4-cyano-4-[(dodecylsulfanylthiocarbonyl) sulfanyl]pentanoic acid (97\%), dimethylamine (40\% in water), 1,3-propanesultone (98\%), 11bromo-1-undecanol (99\%), methanesulfonyl chloride (99.7\%), triisopropylsilane (99\%), trifluoroacetic acid (99\%), 4-vinylbenzyl chloride (>90\% with $500 \mathrm{ppm} t$-butylcatechol), methacryloyl chloride (99\%, with 200 ppm monomethyl ether hydroquinone as stabilizer), 4aminobenzophenone, Dispersed Red 13 (Dye content 95\%), Coumarin 153 (Dye content 99\%), Nile Red (Dye content 98\%), fluorescein isothiocyanate isomer I (FITC >90\%), butylated hydroxytoluene (99\%) and 1,2,4-trichlorobenzene (TCB) (>99\%), $\alpha, \alpha, \alpha$-trifluorotoluene (TFT) (>99\%), borane-tert-butylamine complex powder, (97\%), chloro(triphenylphosphine)gold(I) (>99.9\%), 1-pentanethiol (98\%), 4-methylstyrene, (96\%), 2,2-dimethoxy-2-phenylacetophenone (99\%) and glucose oxidase from Aspergillus niger. $N$-(3-aminopropyl) methacrylamide hydrochloride (APM) (>98\%) was purchased from Polysciences, Inc.; 1-dodecanethiol (98\%) was purchased from Acros Organics; 2,2,2-trifluoroethanol (TFE) (99\%) was purchased from Oakwood Chemicals; tetraethylene glycol (>95\%) was purchased from TCI; triphenylmethanethiol (98+\%) was purchased from Alfa Aesar; Rhodamine Red ${ }^{\text {TM}}-\mathrm{X}$ succinimidyl ester (5-isomer) was purchased from ThermoFisher; and Si wafers (100 mm diameter, one side polished) were purchased from University Wafers. Spectra/Por7 dialysis membranes (3.5 kDa MWCO, pretreated regenerated cellulose tubing), sodium nitrate (>99\%), trimethylamine (>99\%), dichloromethane (99.5\%), acetone (99.5\%), sodium hydroxide (certified ACS), trimethylamine (33 wt\% in ethanol) and diethyl ether (99.9\%) were purchased from Fisher Scientific. Deuterated solvents were purchased from Cambridge Isotope Laboratories and silica gel (40-75 um, 450-550 
$\mathrm{m}^{2} / \mathrm{g}$ ) was purchased from Sorbent Technologies. Tetrahydrofuran (THF) was dried and distilled over sodium/benzophenone ketyl.

Monomer synthesis. Monomers were synthesized according to a published protocol with minor modifications. ${ }^{1}$ In brief, monomer 1 was synthesized by stirring dimethylamine (40 wt $\%$ (aq), 22 $\mathrm{mL}, 196 \mathrm{mmol})$ and 4-vinylbenzyl chloride (17.0 g, $100 \mathrm{mmol})$ in ethanol $(200 \mathrm{~mL})$ and $\mathrm{K}_{2} \mathrm{CO}_{3}$ (41 g) at $65{ }^{\circ} \mathrm{C}$ for $24 \mathrm{~h}$. The reaction mixture was filtered to remove solids and ethanol was removed under vacuum. The crude product was purified by column chromatography on silica gel using hexane:dichloromethane (3:1 v:v with $4 \%$ triethylamine) as the mobile phase. The purified product was obtained as a yellow oil (11.3 g, 59\% yield). To prepare monomer 2, 1,3propanesultone $(5.2 \mathrm{~g}, 41 \mathrm{mmol})$ and 4-vinylbenyl- $N, N$-dimethylamine $(5.5 \mathrm{~g}, 34 \mathrm{mmol})$ were dissolved in acetonitrile $(200 \mathrm{~mL})$ with $0.3 \mathrm{~g}(1.4 \mathrm{mmol})$ butylated hydroxytoluene. The mixture was stirred at $50{ }^{\circ} \mathrm{C}$ for $24 \mathrm{~h}$, then cooled to room temperature. The resultant solid was recovered by filtration, washed with THF, and dried under vacuum to afford 10.7 grams of product (near quantitative yield). Monomer 3 was prepared similarly to that described in the literature. ${ }^{2}$ In brief, a solution of 4-aminobenzophenone $(1.0 \mathrm{~g}, 5.1 \mathrm{mmol})$, methacryloyl chloride $(0.60 \mathrm{~g}, 5.8 \mathrm{mmol})$ and trimethylamine $(0.86 \mathrm{~mL})$ in dichloromethane $(10 \mathrm{~mL})$ was stirred for $24 \mathrm{~h}$ at room temperature in a $20 \mathrm{~mL}$ screw cap glass vial. The reaction mixture was extracted with $1 \mathrm{M} \mathrm{HCl}$, saturated $\mathrm{NaHCO}_{3(\mathrm{aq})}$ and deionized water. Then organic phase was dried over anhydrous sodium sulfate, filtered, and concentrated by rotary evaporation to obtain the desired product as an orange solid (1.26 g, 93\% yield). FITC-substituted monomer 4 was synthesized according to a literature procedure. $^{3}$ In brief, in a $20 \mathrm{~mL}$ screw cap glass vial, $N$-(3-aminopropyl)methacrylamide hydrochloride (186 mg $1.04 \mathrm{mM})$ was combined with trimethylamine (180 uL, $1.3 \mathrm{mM}), \mathrm{DMF}(10$ $\mathrm{mL}$ ), and FITC (331 mg, $0.85 \mathrm{mmol}$ ). The reaction mixture was protected from light and allowed to stir for $72 \mathrm{~h}$. Then, $1 \mathrm{M} \mathrm{HCl}$ was added, which resulted in precipitation of monomer 4 , which was isolated by centrifugation. The precipitate was washed with $1 \mathrm{M} \mathrm{HCl}$ and water, then subjected to lyophilization to yield $480 \mathrm{mg}$ of product.

Polymer synthesis and characterization. Polymers were prepared by reversible additionfragmentation chain transfer (RAFT) polymerization using methods similar to those reported in the literature, ${ }^{1}$ with selection of TFE as the solvent for the preparation of sulfobetaine-substituted polystyrene and 1:1 TFE:water as the solvent for the polymerizations described below. The polymer products were isolated by precipitation into acetone followed by centrifugation (10000 rpm, $5 \mathrm{~min}$ ). The recovered polymers were dissolved in $0.5 \mathrm{M} \mathrm{NaNO}_{3}$ and residual monomers were removed by dialysis over 3 days using $0.5 \mathrm{M} \mathrm{NaNO}_{3(\mathrm{aq})}$, then deionized water. The aqueous polymer solution obtained was lyophilized to recover the polymers as yellow solids, typically on a 1-2 grams scale and $~ 90 \%$ yield.

Polymer molecular weights were estimated by gel permeation chromatography (GPC) using an Agilent 1200 Series system with TFE (containing $20 \mathrm{mM}$ sodium trifluoroacetate) as the mobile phase at $40{ }^{\circ} \mathrm{C}$. The GPC system contained a degasser, isocratic pump, a PFG guard column $(8 \mathrm{x}$ 
$50 \mathrm{~mm}$ ), a series of three PFG analytical linear M columns ( 8 x $300 \mathrm{~mm}$, particle size $=7 \mu \mathrm{m})$, and a refractive index detector calibrated with poly(methyl methacrylate) standards.

The compositions of PZAs and PZA-50 with benzophenone-substituted comonomer were obtained by ${ }^{1} \mathrm{H}$ NMR spectroscopic integration of $5 \mathrm{mg} / \mathrm{mL} \mathrm{D}_{2} \mathrm{O}$ solutions. The mole percent of FITC in PZA50-FITC was determined by UV-Vis spectroscopy. The results of polymer characterization are presented in Figure S1, Table S1 and Table S2.

PZA-30, 50, and 67 were recovered as beige solids after lypophilization: ${ }^{1} \mathrm{H}$ NMR (500 $\mathrm{MHz}$, $\left.\mathrm{D}_{2} \mathrm{O}\right), \delta$, ppm: $7.14(\mathrm{ArH}), 6.51(\mathrm{ArH}),(4 \mathrm{H}$ of monomer 1 and $4 \mathrm{H}$ of monomer 2$), 4.40\left(\mathrm{CH}_{2}-\mathrm{N}^{+}\right)$ (2H of monomer 2), $4.10\left(\mathrm{CH}_{2}-\mathrm{N}\right)$ (2H of monomer 1), $3.2\left(\mathrm{CH}_{2}-\mathrm{SO}_{4}{ }^{-}\right)$(2H of monomer 2), 2.90 $\left(\mathrm{CH}_{3}-\mathrm{N}^{+}, \mathrm{CH}_{2}-\mathrm{N}^{+}\right)$(8H of monomer 2), $2.60\left(\mathrm{CH}_{3}-\mathrm{N}\right)\left(6 \mathrm{H}\right.$ of monomer 1), $2.20\left(\mathrm{CH}_{2}\right)(2 \mathrm{H}$ of monomer 2) 0.8-2.0 (backbone $3 \mathrm{H}$ of monomer 1 and $3 \mathrm{H}$ of monomer 2). Polymer composition was calculated by integrating $\mathrm{CH}_{2}$ signals at $\delta 4.40$ (2 $\mathrm{H}$ of monomer 2) against the signal at $\delta 4.10$ (2H of monomer 1). ${ }^{13} \mathrm{C}$ NMR $\left(500 \mathrm{MHz}, \mathrm{D}_{2} \mathrm{O}, \delta, \mathrm{ppm}\right),:$ 17.38, 39.55, 40.88, 46.53, 48.69, 59.38, $60.82,66.55,123.74,125.98,127.52,129.70,131.68$.

PZA50, containing benzophenone-substituted methacrylamide, was recovered as a yellow solid after lyophilization: $\left(\mathrm{M}_{\mathrm{n}} 35.2 \mathrm{kDa}\right.$ and $\left.\mathrm{M}_{\mathrm{w}} 31.4 \mathrm{kDa}\right) .{ }^{1} \mathrm{H}$ NMR (500 MHz, $\left.\mathrm{D}_{2} \mathrm{O}\right), \delta$, ppm: 7.13 $(\mathrm{ArH}) 6.65(\mathrm{ArH}),(4 \mathrm{H}$ from monomer $1,4 \mathrm{H}$ from monomer $2,9 \mathrm{H}$ from monomer 3$), 4.40\left(\mathrm{CH}_{2-}\right.$ $\mathrm{N}^{+}$) (2H from monomer 2), $4.10\left(\mathrm{CH}_{2}-\mathrm{N}\right)(2 \mathrm{H}$ of monomer 1$), 3.2\left(\mathrm{CH}_{2}-\mathrm{SO}_{4}{ }^{-}\right)$(2H of monomer 2), $2.90\left(\mathrm{CH}_{3}-\mathrm{N}^{+}, \mathrm{CH}_{2}-\mathrm{N}^{+}\right)(8 \mathrm{H}$ from monomer 2$), 2.60\left(\mathrm{CH}_{3}-\mathrm{N}\right)(6 \mathrm{H}$ from monomer $\mathbf{1}), 2.20\left(\mathrm{CH}_{2}\right)$ ( $2 \mathrm{H}$ from monomer 2), 0.8-2.0 (backbone $3 \mathrm{H}$ from monomer $1,3 \mathrm{H}$ from monomer 2 and $5 \mathrm{H}$ from monomer 3). Polymer composition was calculated by integrating the ArH signals from $\delta 6-8 \mathrm{ppm}$ (4H from monomer 1, $4 \mathrm{H}$ from monomer $2,9 \mathrm{H}$ from monomer 3 ) against the methylene resonance at $\delta 4.40$ (2H of monomer 2 ) and other peaks at $\delta 4.10$ (2H of monomer $\mathbf{1})$.

PZA50-FITC, containing FITC-substituted methacrylamide, was recovered as a yellow solid after lyophilization: $\left(\mathrm{M}_{\mathrm{n}} 38.7 \mathrm{kDa}\right.$ and $\left.\mathrm{M}_{\mathrm{w}} 44.7 \mathrm{kDa}\right) .{ }^{1} \mathrm{H} \mathrm{NMR}\left(500 \mathrm{MHz}, \mathrm{D}_{2} \mathrm{O}\right), \delta$, ppm: $7.14(\mathrm{ArH})$ $6.50(\mathrm{ArH}),(4 \mathrm{H}$ from monomer $1,4 \mathrm{H}$ from monomer 2 and $9 \mathrm{H}$ from monomer 4$), 4.40\left(\mathrm{CH}_{2}-\mathrm{N}^{+}\right)$ (2H from monomer 2), $4.10\left(\mathrm{CH}_{2}-\mathrm{N}\right)(2 \mathrm{H}$ from monomer 1$), 3.2\left(\mathrm{CH}_{2}-\mathrm{SO}_{4}{ }^{-}\right)$( $2 \mathrm{H}$ from monomer 2), $2.86\left(\mathrm{CH}_{3}-\mathrm{N}^{+}, \mathrm{CH}_{2}-\mathrm{N}^{+}\right)(8 \mathrm{H}$ from monomer 2$), 2.61\left(\mathrm{CH}_{3}-\mathrm{N}\right)(6 \mathrm{H}$ from monomer 1$), 2.17\left(\mathrm{CH}_{2}\right)$ (2H from monomer 2), 2.2-3.5 $\left(\mathrm{CH}_{2}-\mathrm{N}\right.$ peaks from monomer 4 within this broad signal range), 0.8-2.0 (backbone $3 \mathrm{H}$ from monomer $\mathbf{1}, 3 \mathrm{H}$ from monomer $\mathbf{2}$ and $5 \mathrm{H}$ from monomer 4 ). UV-Vis absorption of a TFE solution of PZA50-FITC, using $\lambda_{\max }$ at $482 \mathrm{~nm}$, indicated an approximately 0.5 mole percent of FITC.

Polymer solution properties. Transmittance measurements were performed on $1 \mathrm{mg} / \mathrm{mL}$ polymer solutions at room temperature and $550 \mathrm{~nm}$, using a Hitachi U-3010 spectrophotometer equipped with a temperature-controlled cuvette holder and TC-1 temperature controller (Quantum Northwest). Solution $\mathrm{pH}$ was measured using a Beckman Coulter PHI $560 \mathrm{pH}$ meter with Orion ${ }^{\mathrm{TM}}$ 9110DJWP Double Junction pH Electrode. The cloud points, reported as the temperature at 50\% transmittance, were measured at $550 \mathrm{~nm}$ at a heating rate of $1{ }^{\circ} \mathrm{C} / \mathrm{min}$. Liquid-in-liquid droplets 
(Figure S9) were characterized using an Olympus Fluorescence Microscope BX51 and $1 \mathrm{mg} / \mathrm{mL}$ solutions.

Emulsion preparation and characterization. Oil-in-water emulsions were prepared by loading $1 \mathrm{~mL}$ of a $10 \mathrm{mg} / \mathrm{mL}$ aqueous polymer solutions at $\mathrm{pH}$ 6-7 into a $7 \mathrm{~mL}$ glass vial with $1 \mathrm{~mL}$ of the selected organic solvent(s) (PZA67, 50, 30, PZA50-Ph2CO, PZ50A-FITC, PSBS). For nonsticky emulsion experiments, the polymer solution in the glass vial was vortexed for $1 \mathrm{~min}$ at 1200 $\mathrm{rpm}$. To prepare sticky emulsions, the polymer solution and selected oil were vortexed for $15 \mathrm{~s}$ at $1200 \mathrm{rpm}$, after which $10 \mathrm{uL}$ of $5 \mathrm{M} \mathrm{NaOH}_{(\mathrm{aq})}$ was added, and the resultant mixture was vortexed for $1 \mathrm{~min}$ at $1200 \mathrm{rpm}$. For sticky emulsions kept at $\mathrm{pH} \mathrm{6-7,} \mathrm{the} \mathrm{glass} \mathrm{vial} \mathrm{was} \mathrm{vortexed} \mathrm{for} 15 \mathrm{~s}$

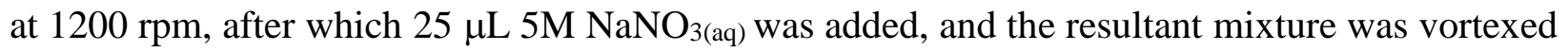
for $1 \mathrm{~min}$ at $1200 \mathrm{rpm}$. The formed emulsions were kept at room temperature $\left(\sim 23{ }^{\circ} \mathrm{C}\right)$ for $\sim 2 \mathrm{~h}$ and the supernatant was removed carefully by syringe. The oil volume fraction of the emulsions was calculated as $\varphi_{\text {oil }}=\mathrm{V}_{\text {oil }} /\left[\mathrm{V}_{\text {oil }}+\left(\mathrm{V}_{\text {supernatant }}\right)\right]$.

Emulsion gel preparation. Plastic molds were printed using a FlashForge creator pro 3D printer with polylactide resin. The emulsions, after removal of supernatant, were loaded into a $1 \mathrm{~mL}$ syringe fitted with a blunt-tipped $20 \mathrm{G}$ needle (inner diameter $=0.603 \mathrm{~mm}$ ) and injected into the molds by hand. Then molds were removed immediately after injection.

Preparation and characterization of supracolloidal fibers. Emulsions were loaded into a $1 \mathrm{~mL}$ syringe fitted with a blunt-tipped $20 \mathrm{G}$ needle (inner diameter $0.603 \mathrm{~mm}$ ). The emulsion was pushed through the needle (by hand) into capillary tubes (O.D. 1.5-1.8 mm, wall thickness 0.2 $\mathrm{mm}$ ). Multi-segment fibers were prepared by sequential injection of different emulsions into the capillary tubes. To crosslink the fibers, the UV-crosslinkable emulsions in the capillary tubes were fixed onto a plate and subjected to $365 \mathrm{~nm} \mathrm{UV} \mathrm{light}\left(1.6 \times 10^{5} \mu \mathrm{J} / \mathrm{cm}^{2}\right)$ for $15 \mathrm{~min}$ on each side of the tubes. To test the $\mathrm{pH}$ response, fibers (crosslinked and non-crosslinked) were injected into a glass Petri dish containing deionized water, followed by addition of $1 \mathrm{M} \mathrm{HCl}$ in close proximity to a fiber end. Photographs of the fibers containing fluorescent dyes were taken by a Canon 6D camera with MP-E $65 \mathrm{~mm}$ Prime lens equipped with filter of >505 nm and Canon Macro Twin Lite Mt-26EX-RT Flash equipped with filter of 480-505 nm.

Surface tension measurements. Interfacial tension values were recorded on a Data Physics OCA15 plus tensiometer in pendant drop mode, using aqueous polymer solutions at different $\mathrm{pH}(0.5$ mg/mL PZA-50) and a 21 Ga blunt needle. For PZA-50, experiments at $\mathrm{pH} 7$ were performed in salt-free water and those at $\mathrm{pH} 9$ were performed in $250 \mathrm{mM} \mathrm{NaNO}_{3}$ (aq). For the SB-substituted polystyrene (PSBS in Figure S1; black line in Figure 2), experiments were performed in $250 \mathrm{mM}$ $\mathrm{NaNO}_{3(\mathrm{aq})}$ water at $\mathrm{pH} 7$.

Rheology measurements. A stress-controlled rheometer (Physica MCR 301; Anton Paar) was used to measure rheological properties at $23{ }^{\circ} \mathrm{C}$. To minimize the effect of wall slip, a parallel plate geometry was employed with an arithmetic average roughness $\left(\mathrm{R}_{\mathrm{a}}\right)$ of 6-7 $\mu \mathrm{m}$ and a plate diameter of $50 \mathrm{~mm}$. 
Fluorescence recovery experiments. Fluorescence recovery experiments, following photobleaching, were performed on a Nikon A1 resonant scanning confocal microscope with TIRF module. The samples were bleached with a $408 \mathrm{~nm}$ laser for $2 \mathrm{~min}$ and fluorescence recovery was monitored by imaging the samples at $488 \mathrm{~nm}$ in $30 \mathrm{~s}$ increments for $600 \mathrm{~s}$ in total. The emulsions and crosslinked fibers utilized in these experiments were prepared at either $\mathrm{pH}$ 6.5-7 or $\mathrm{pH} 12$ 12.5, with TCB as the oil phase. For experiments involving the cross-linked droplet fibers, the fiber was cross-linked fiber while in the capillary tube at $365 \mathrm{~nm} \mathrm{UV}$ (for $15 \mathrm{~min}$ on each side of the tube). The emulsion droplets used in the experiments were prepared about 1-2 $\mathrm{h}$ prior to the measurement; the supernatant was removed before the measurement and the emulsions/fiber were placed into deionized water at $\mathrm{pH} 7$ or 12 .

Preparation of Au NPs. Au NPs were prepared according to a published paper with minor procedural adjustments. ${ }^{4}$ Briefly, $\mathrm{AuPPh}_{3} \mathrm{Cl}(200 \mathrm{mg}, 0.4 \mathrm{mM})$ was stirred as a clear solution in $n$ dodecanethiol $(202 \mathrm{uL}, 0.83 \mathrm{mM})$ and benzene $(15 \mathrm{~mL})$. Then tert-butylamine-borane complex (350 mg, $4 \mathrm{mM}$ ) was added as a powder. The mixture was stirred at $55{ }^{\circ} \mathrm{C}$ for one hour, then allowed to cool to room temperature. The mixture was washed with ethanol and separated by centrifugation (9000 rpm, 3 x $10 \mathrm{~min}$ ) to afford a dark powder that was dried under vacuum. Transmission electron microscopy of the NPs is shown in Figure S18.

Synthesis of fluorescent GOx. Glucose oxidase $(7.9 \mathrm{mg}, 49 \mathrm{nmol})$ was dissolved in $\sim 1 \mathrm{~mL}$ phosphate buffer solution (100 mM, pH 6). A separate solution comprised of Rhodamine Red-X $(1.0 \mathrm{mg}, 1.3 \mu \mathrm{mol})$ in $\sim 1 \mathrm{~mL}$ methanol was added to the GOx solution. This mixture was stirred at room temperature for 2-3 hours and then subjected to several iterations of centrifugal dialysis (Amicon Ultra 15, 3K MWCO, EMD Millipore). The supernatant was removed and lyophilized for three days to yield the desired product as a light orange/pink solid.

Preparation of Au-patterned Si wafers. Microposit S1813 photoresist (Shipley, Inc.) was spincoated onto a Si test wafer (100 mm diameter, one side polished, University Wafers), which was subsequently baked at $100{ }^{\circ} \mathrm{C}$ for $1 \mathrm{~min}$. The wafer was loaded into the SUSS MicroTec MA6 Mask Aligner, along with desired photomask (4 in. Sodalime AR Chrome Mask, Benchmark Technologies), using contact mode; the wafer was then exposed to UV light ( 450-500 nm) for 6 seconds. The pattern on the wafer was developed in Microposit MF-319 Developer (DG) (Rohm and Haas Electronic Materials LLC) for $50 \mathrm{~s}$, rinsed in DI water for $2 \mathrm{~min}$, and thoroughly dried with $\mathrm{N}_{2(\mathrm{~g})}$. Using e-beam evaporation (CHA SE-600 equipped with an AJA 600 cryo-pump), a 50 nm layer of gold (99.9\%, Kurt J. Lesker Company) was then deposited onto the wafer with a 10 $\mathrm{nm}$ chromium (99.9\%, Kurt J. Lesker Company) underlayer for adhesion. The wafer was soaked in acetone for lift-off before rinsing with acetone and isopropanol, then drying under $\mathrm{N}_{2(\mathrm{~g}) \text {. }}$

Enzyme immobilization. A self-assembled monolayer was formed on the gold patch of the wafers with a quaternary ammonium thiol linker (Figure S11) synthesized as described in the literature. ${ }^{5}$ The linker was dissolved in methanol $(3 \mathrm{mg} / \mathrm{mL})$, added to a petri dish containing 
several wafer pieces, and allowed to incubate at room temperature for 48 hours while covered.

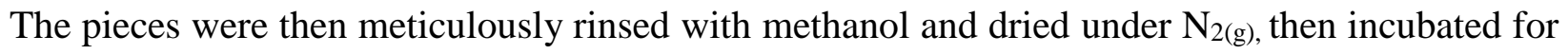
4-5 hours in a GOx solution ( $3 \mathrm{mg} / \mathrm{mL}$ in PBS). The wafer pieces were then rinsed with DI water,

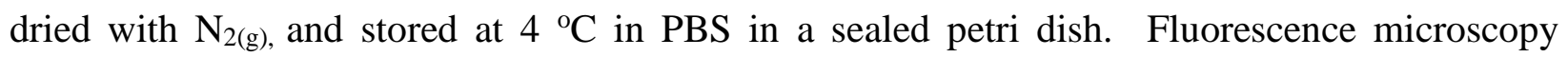
confirmed successful enzyme immobilization (Figure S12).

\section{S.2 Supporting Figures}

(a) Chemical structure of monomers
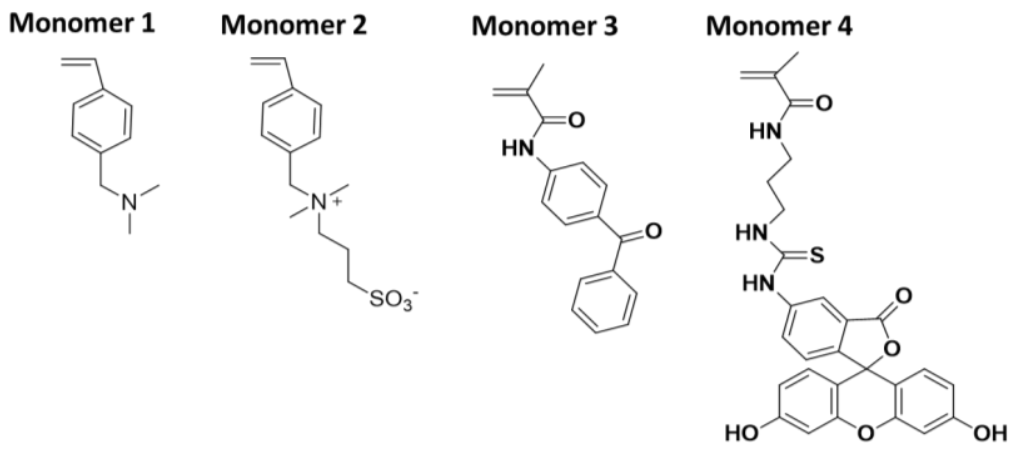

\section{Chemical structure of polymers}
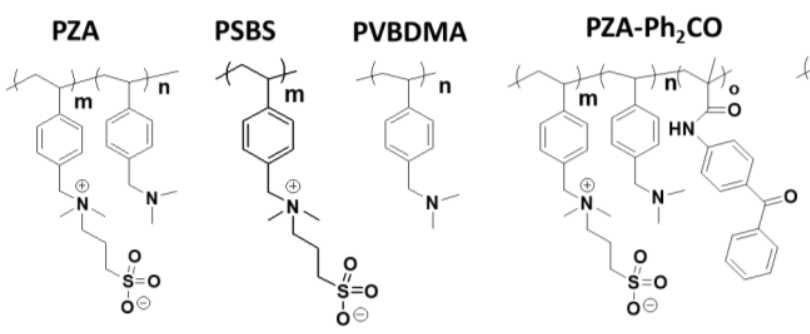

PZA-FITC

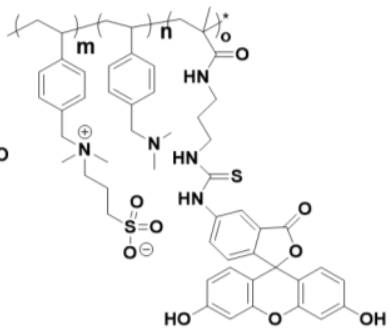


(b) Praso

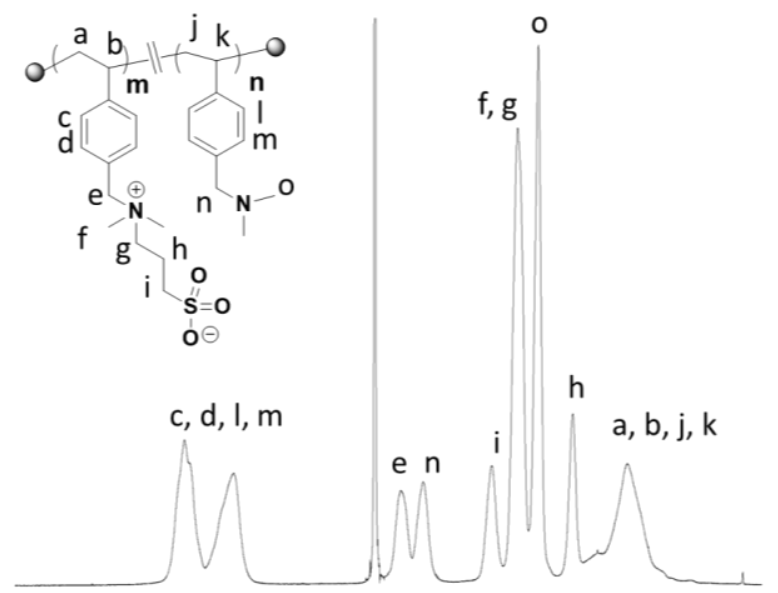

\begin{tabular}{llllllllllllllllllllllll}
\hline 9.0 & 8.5 & 8.0 & 7.5 & 7.0 & 6.5 & 6.0 & 5.5 & 5.0 & 4.5 & 4.0 & 3.5 & 3.0 & 2.5 & 2.0 & 1.5 & 1.0 & 0.5 & $\mathrm{ppm}$
\end{tabular}

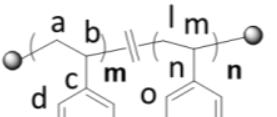

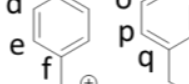

$\stackrel{f}{\mathrm{~g}} \stackrel{\oplus}{\mathrm{N}} \mathrm{h} \stackrel{\mathrm{r}}{\mathrm{N}}-\mathrm{s}$

$i j$

$\mathrm{k} \stackrel{\mathrm{s}=0}{\mathrm{~s}=0}$

$d, e, f$

$0 \quad 0, p, q$
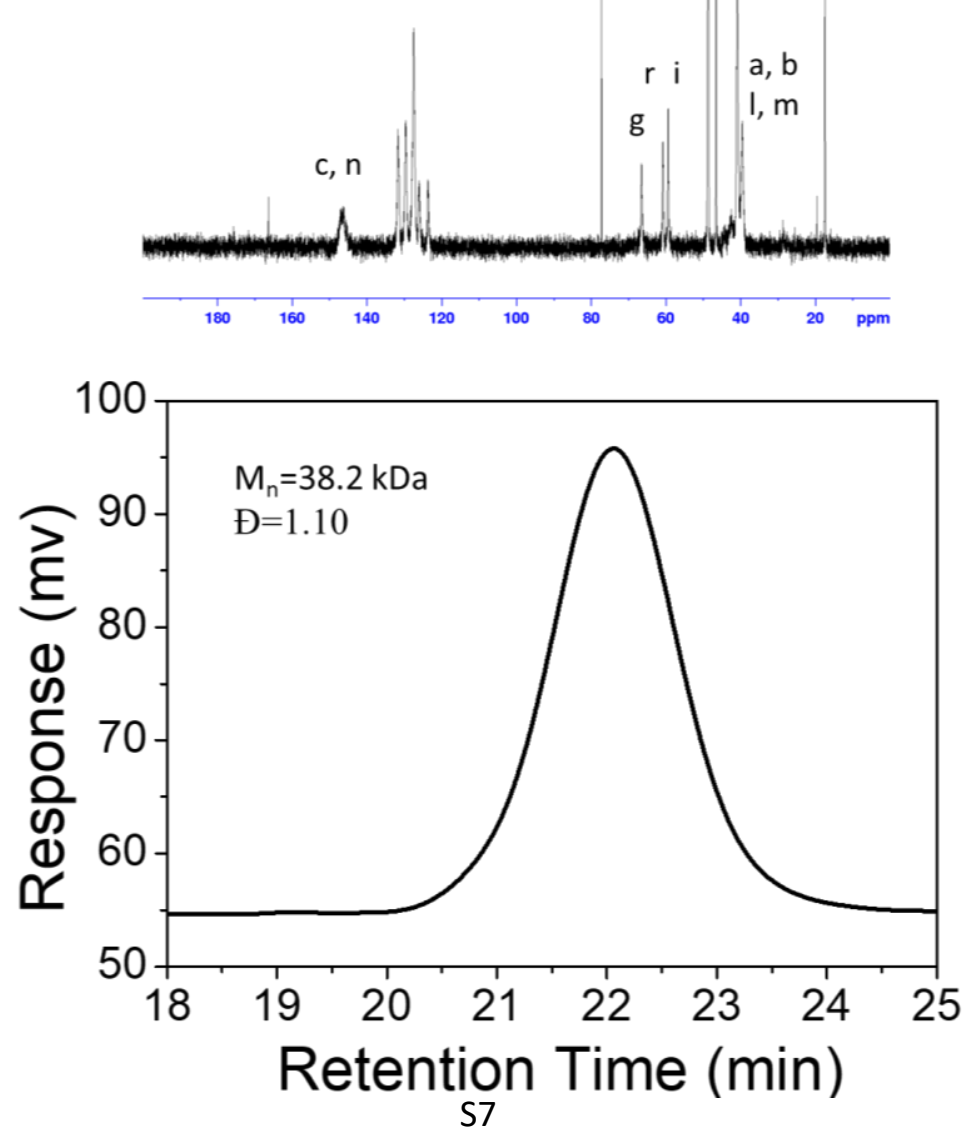

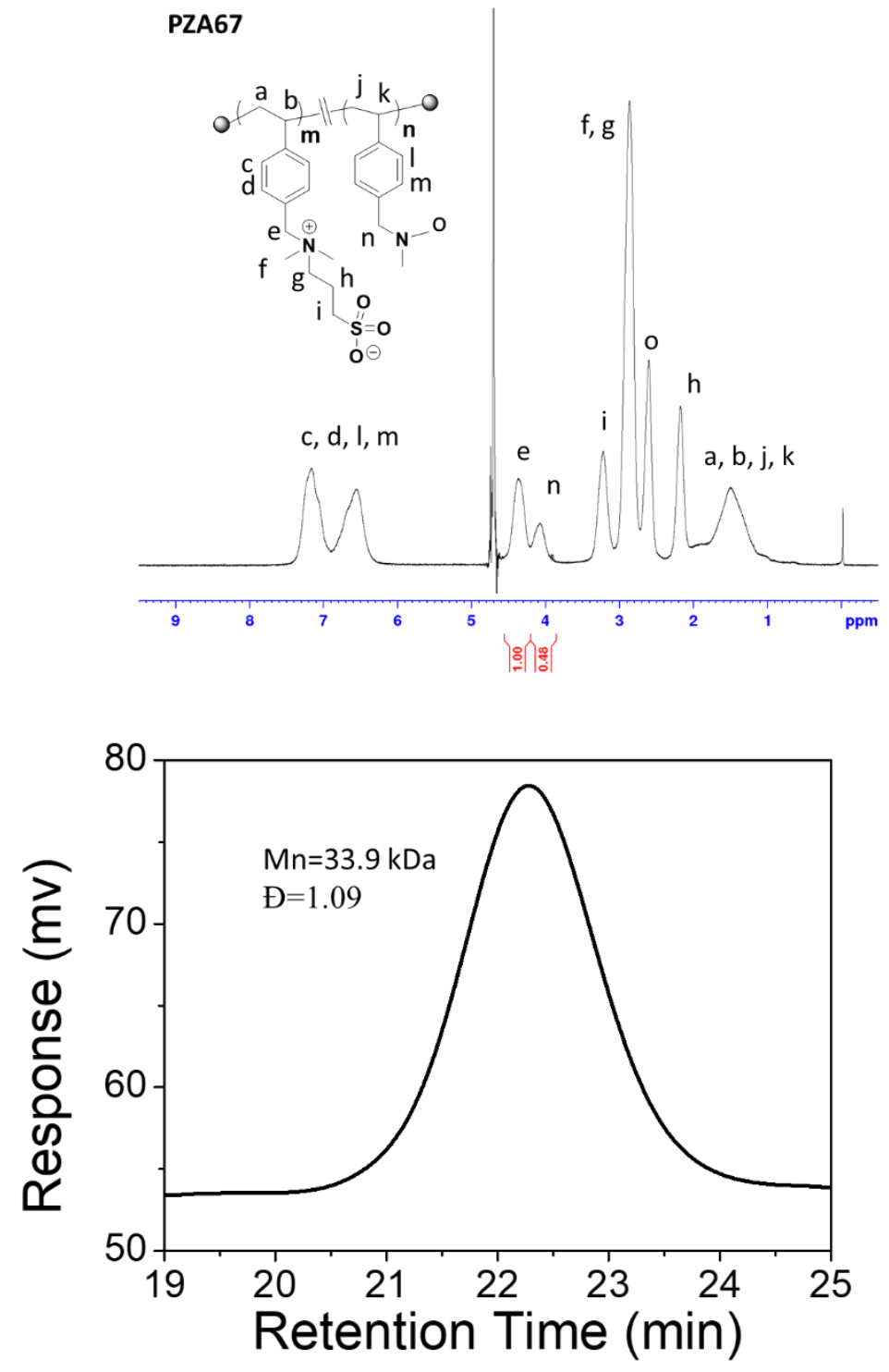

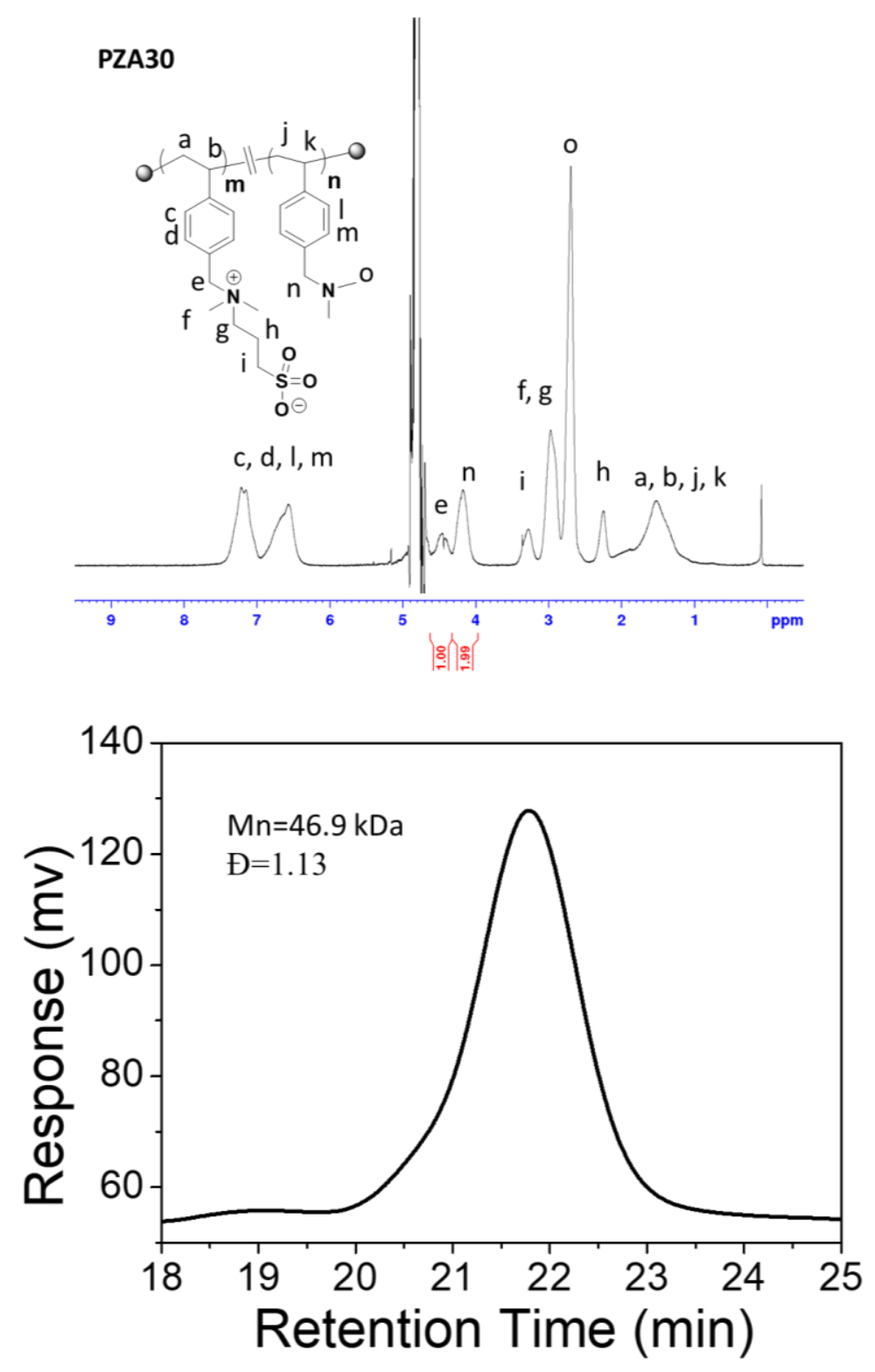

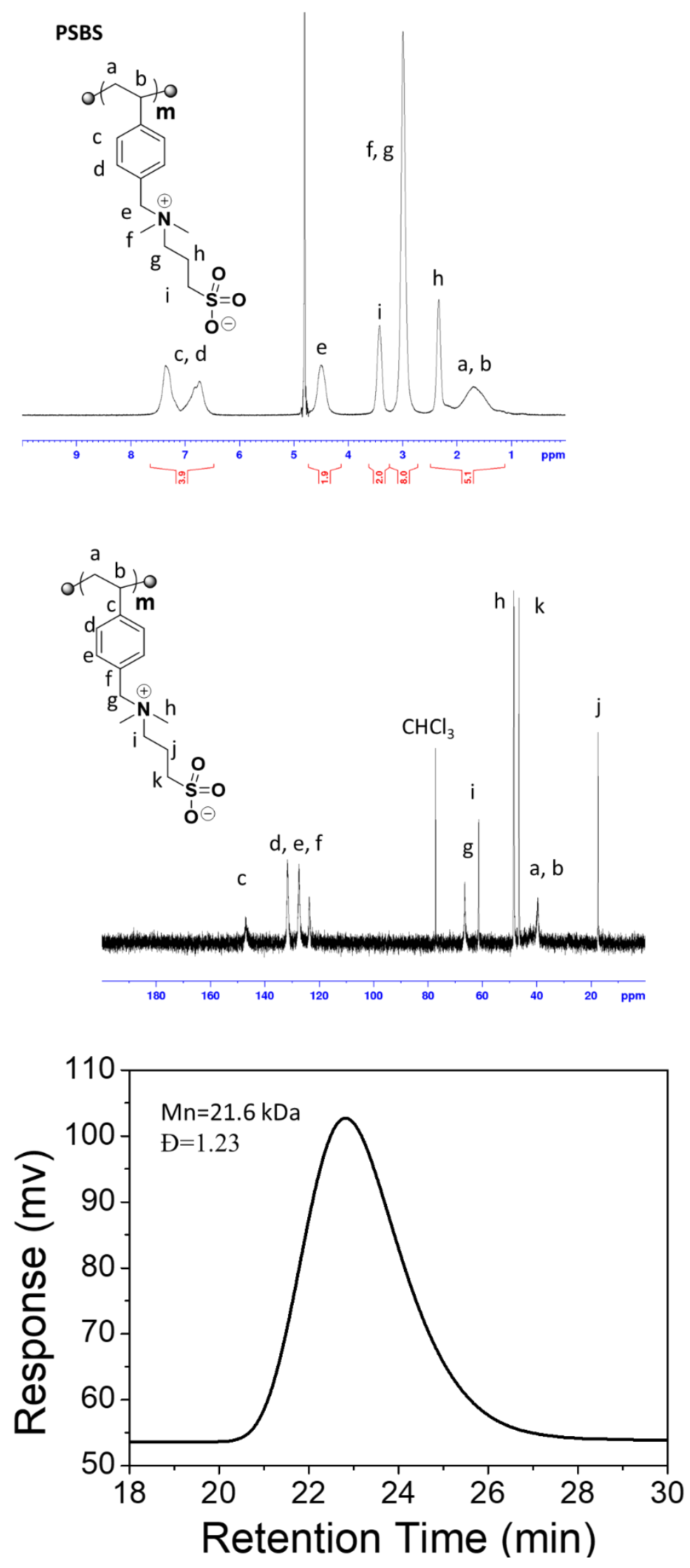

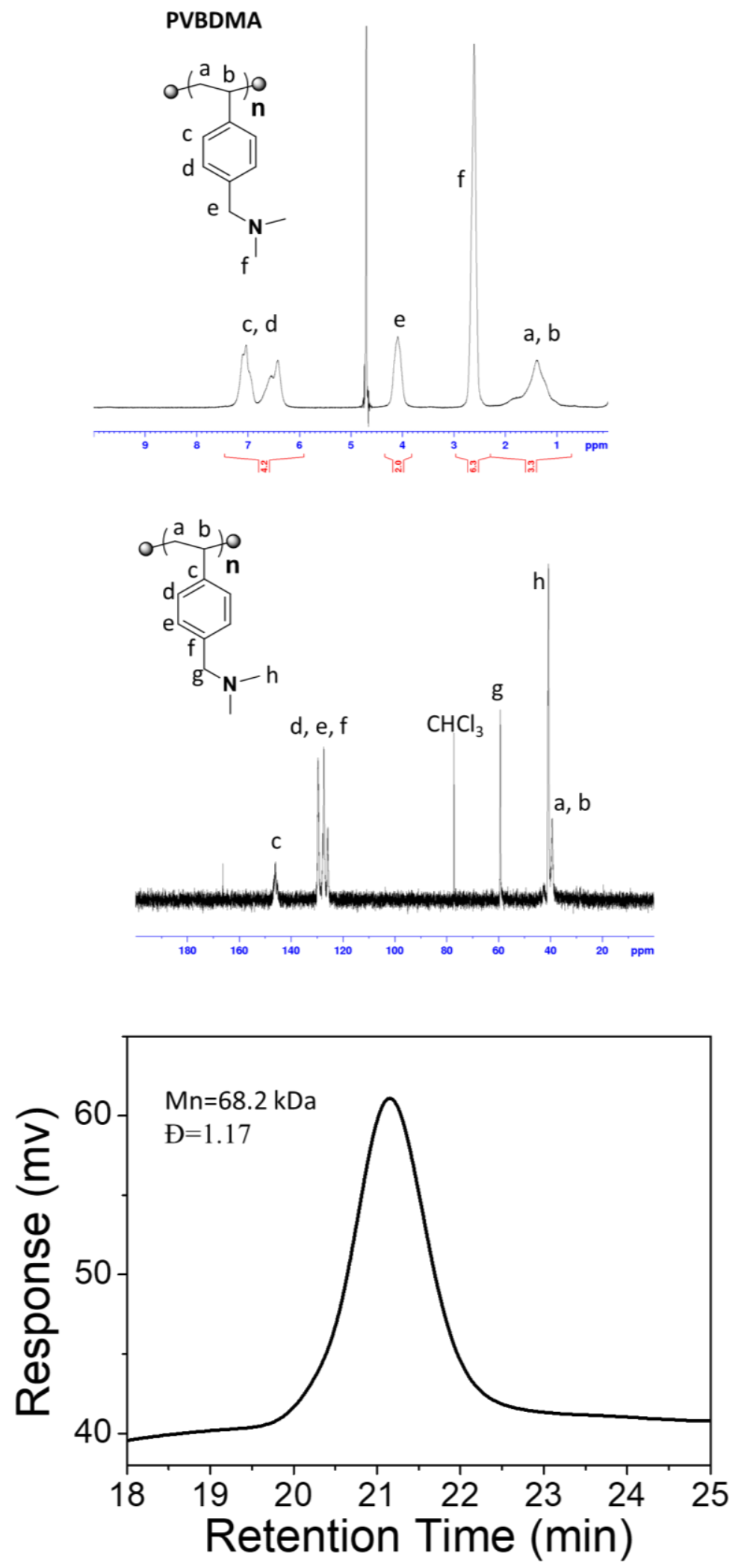

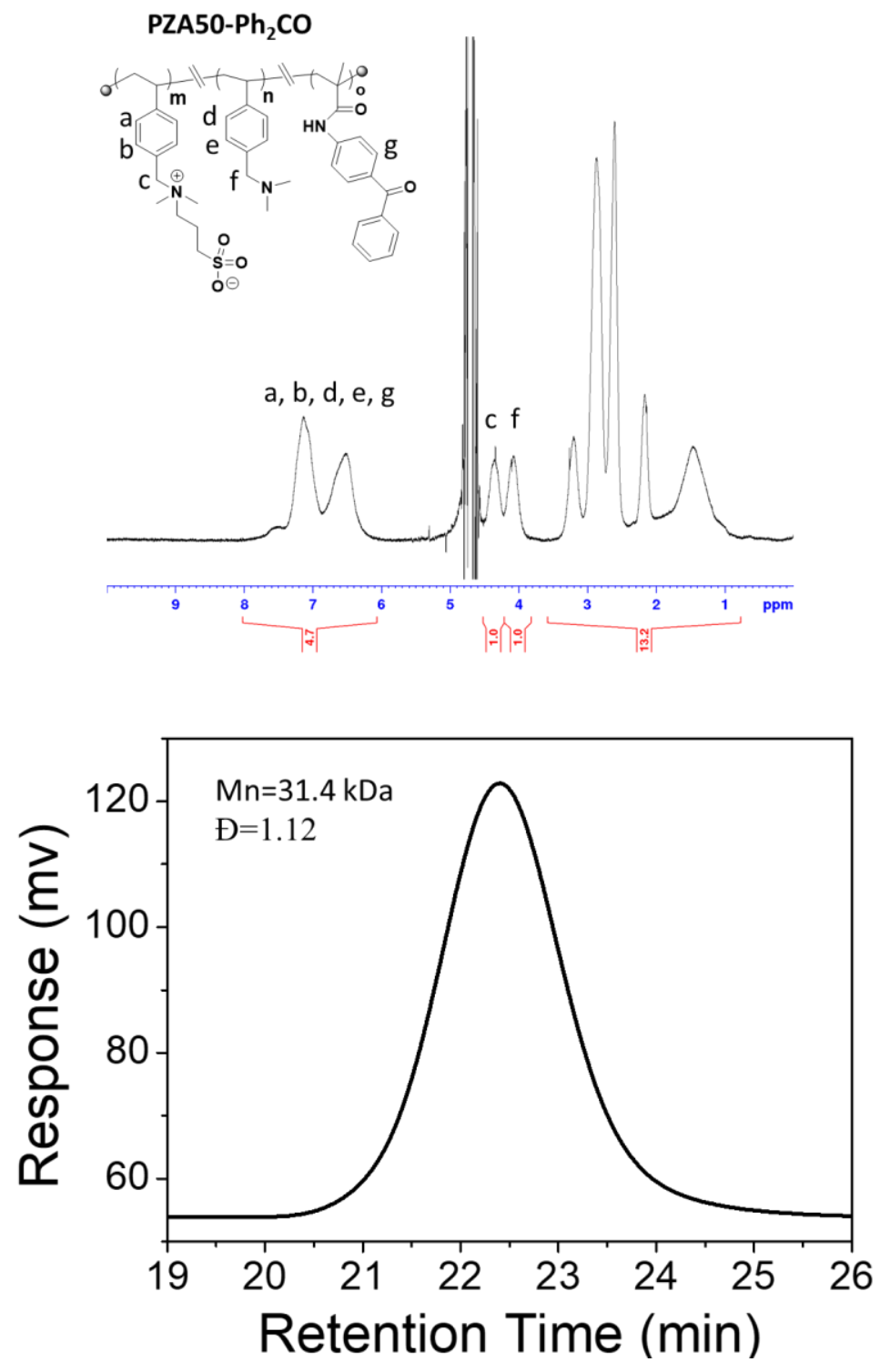

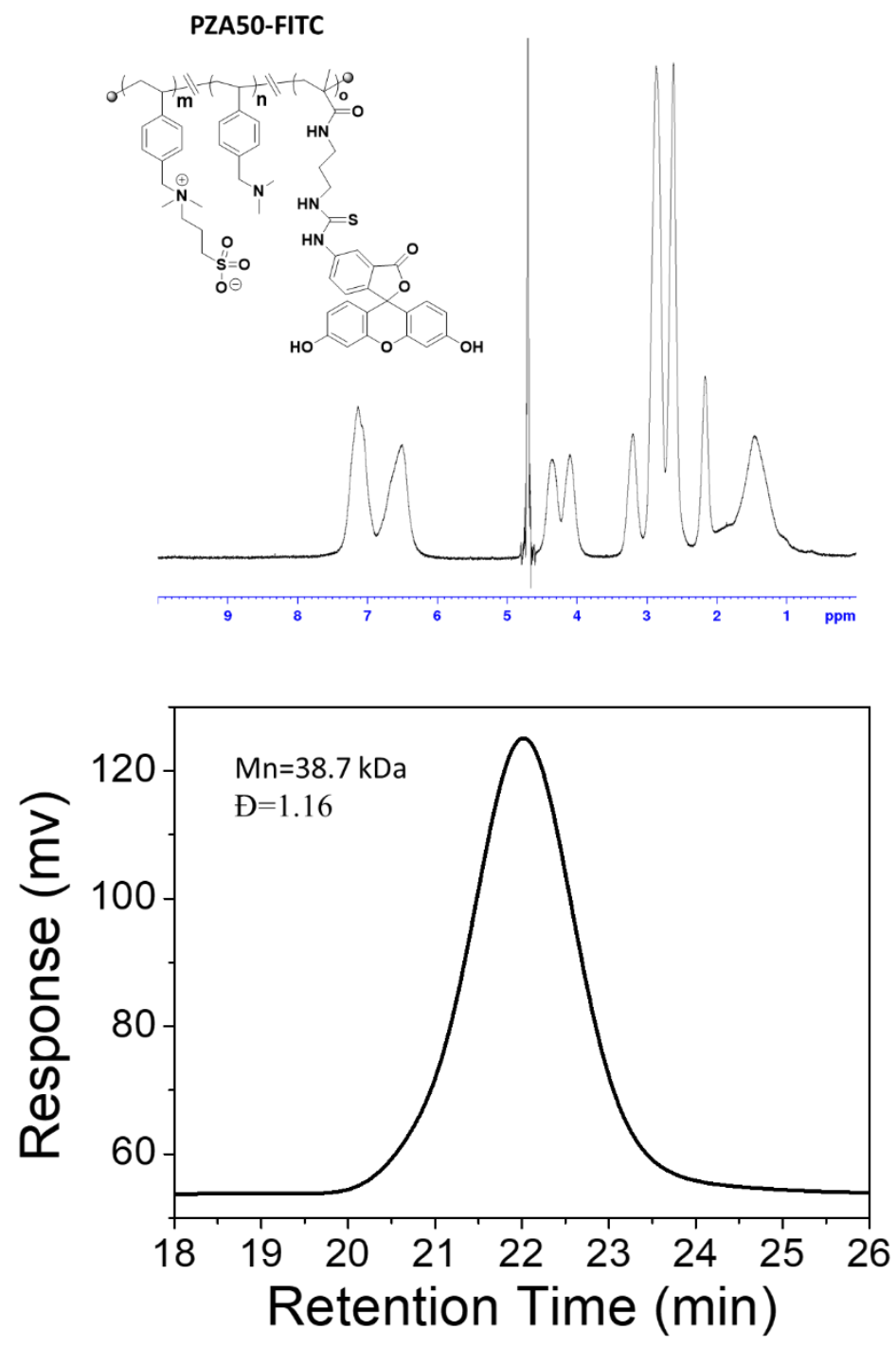

Figure S1. Chemical structures of monomers (a) and polymers (b) utilized in this work and their corresponding NMR spectra and GPC traces. 
Table S1. GPC data and results of monomer ratios integrated into the polymers

\begin{tabular}{lllll}
\hline Polymer & $\mathrm{M}_{\mathrm{n}}(\mathrm{kDa})$ & $\mathrm{M}_{\mathrm{w}}(\mathrm{kDa})$ & $\mathrm{D}$ & Ratio (m:n:o) \\
\hline PZA-50 & 38.2 & 42.1 & 1.10 & $50: 50^{1}$ \\
PZA-67 & 33.9 & 37.1 & 1.09 & $67: 33^{1}$ \\
PZA-30 & 46.9 & 52.9 & 1.13 & $30: 70^{1}$ \\
PSBS & 21.6 & 26.5 & 1.23 & $\mathrm{~N} / \mathrm{A}$ \\
PVBDMA & 68.2 & 79.9 & 1.17 & $\mathrm{~N} / \mathrm{A}$ \\
$\begin{array}{l}\text { PZA-50- } \\
\text { Ph2CO }\end{array}$ & 31.4 & 35.2 & 1.12 & $46.4: 46.4: 7.2^{1}$ \\
PZA50-FITC & 38.7 & & 1.16 & $49.25: 49.25: 0.5^{2}$ \\
\hline $\begin{array}{l}\text { 1. Calculated by integration of }{ }^{1} \mathrm{H} \text { NMR spectra. } \\
\text { 2. Calculated by UV-Vis spectroscopy. }\end{array}$
\end{tabular}

Table S2. Summary of UV-Vis absorption data for PZA50-FITC

\begin{tabular}{ccccc}
\hline & PZA50-FITC (mg) & abs 482 nm & FITC in polymer (mg) & \% FITC \\
\hline 1 & 4.87 & 0.430 & 0.022 & 0.51 \\
2 & 5.58 & 0.517 & 0.025 & 0.47 \\
3 & 4.40 & 0.425 & 0.09 & 0.62 \\
\hline
\end{tabular}



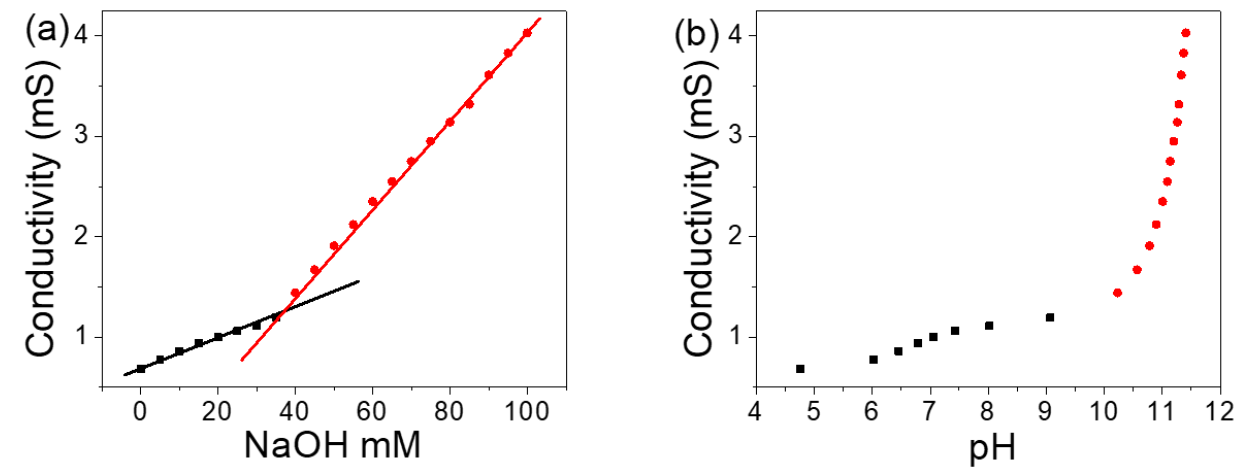

Figure S2. Conductivity of PZA-50 solutions as a function of (a) $\mathrm{NaOH}$ concentration and (b) $\mathrm{pH}$, for a-d: [polymer] $=1 \mathrm{mg} / \mathrm{mL}$. 

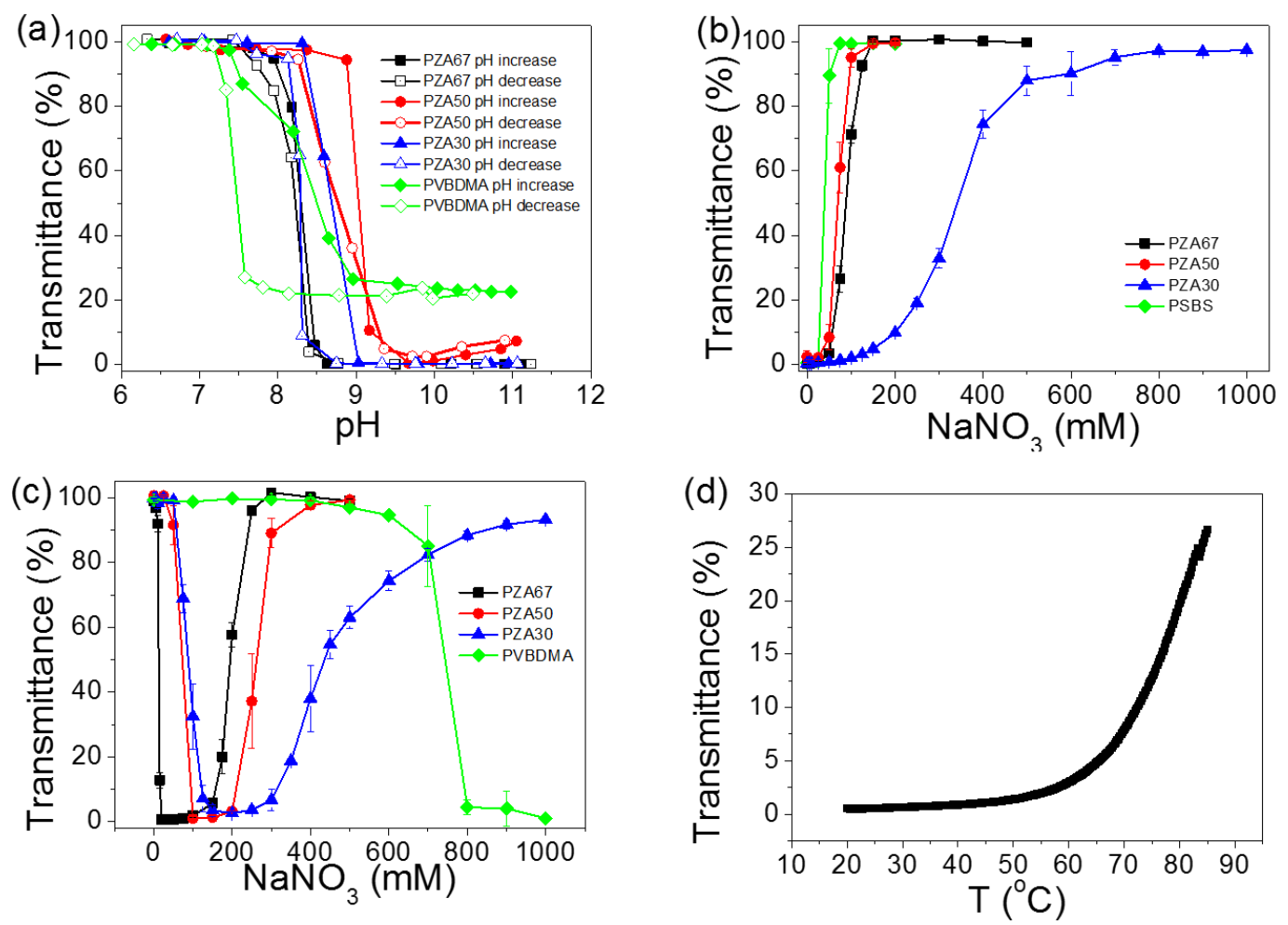

Figure S3. (a) Transmittance of polymer solutions as a function of $\mathrm{pH}$; (b) transmittance of polymer solutions as a function of salt concentration at $\mathrm{pH} \mathrm{9.2;} \mathrm{(c)} \mathrm{transmittance} \mathrm{of} \mathrm{polymer}$ solutions as a function of salt concentration at low pH (PZA-67: pH 7.3, PZA-50: pH6.6; PZA30; $\mathrm{pH}$ 6.8); (d) transmittance of polymer $\mathbf{2}$ solution as a function of temperature; for a-d: [polymer] $=1 \mathrm{mg} / \mathrm{mL}$. 


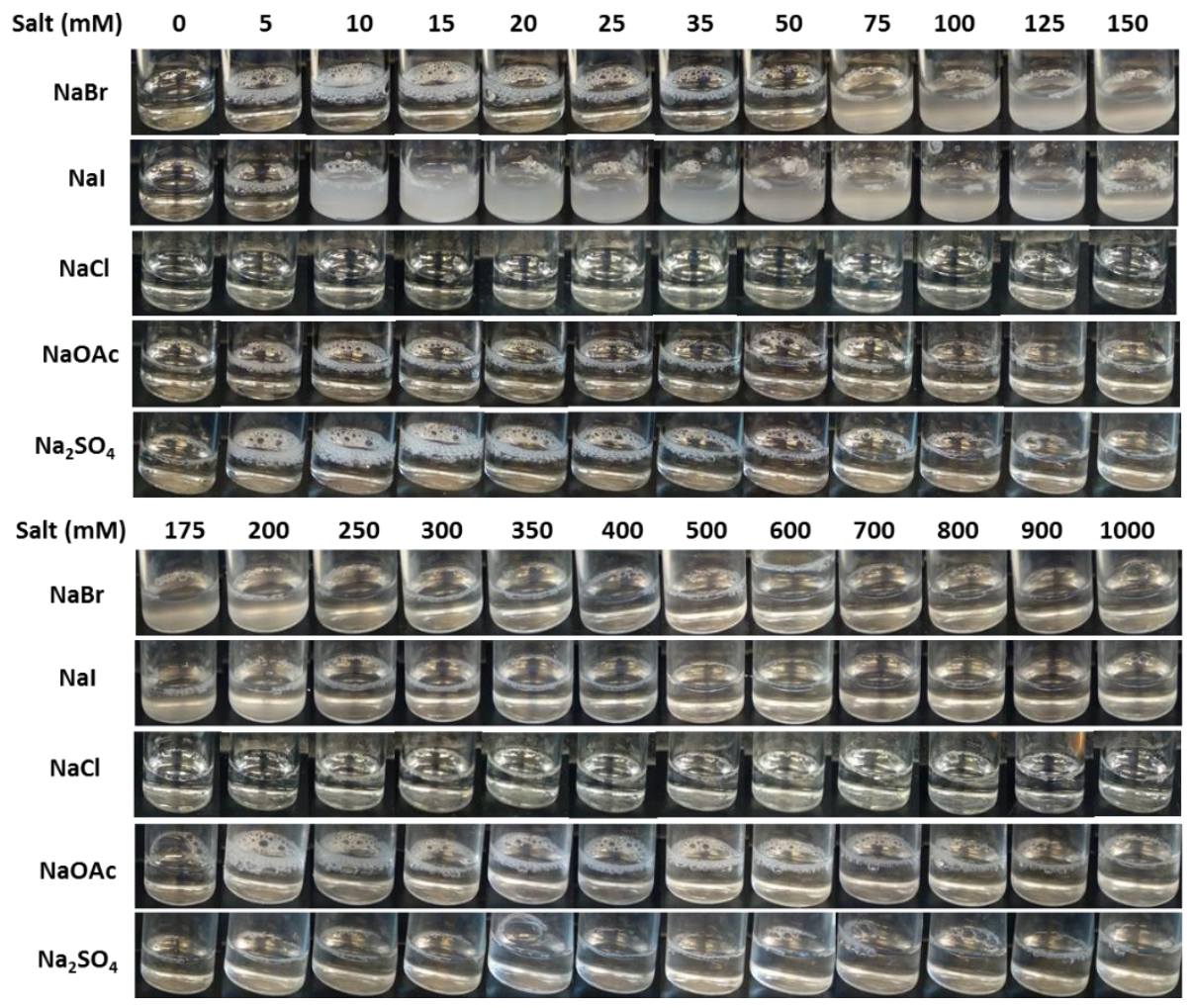

Figure S4. Photographs of vials of PZA-50 aqueous solutions $(1 \mathrm{mg} / \mathrm{mL})$ showing the effect of salt composition on transmittance $(\mathrm{pH}=6.7$ for $\mathrm{NaCl}$ solution and 7.2 for the other solutions). 


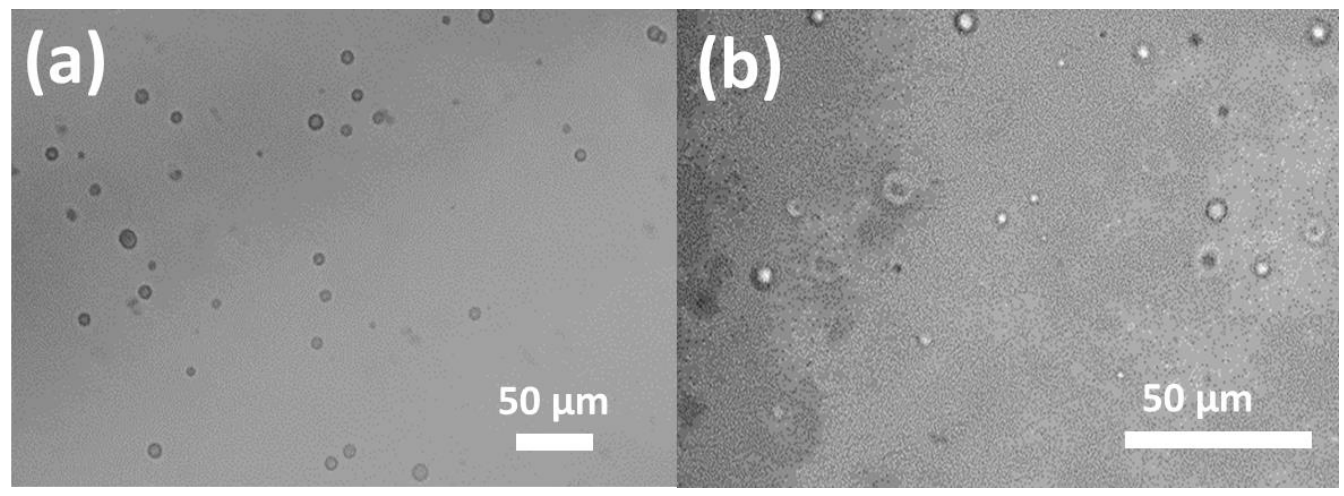

Figure S5. Optical micrographs of PZA-50 solution (a) $\mathrm{pH}$ at 9.8 and (b) $\mathrm{pH}$ at 7.0 with $150 \mathrm{mM}$ $\mathrm{NaNO}_{3}$ (aq), [polymer] $=1 \mathrm{mg} / \mathrm{mL}$. 
(a) PZA 67

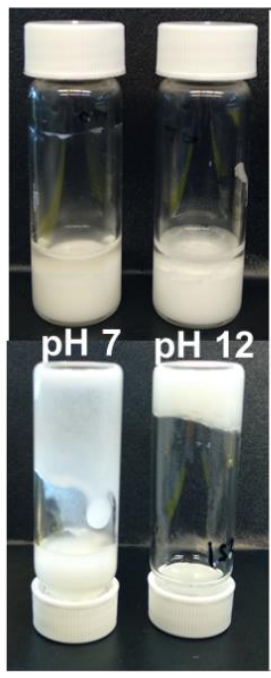

(b)
PZA 50

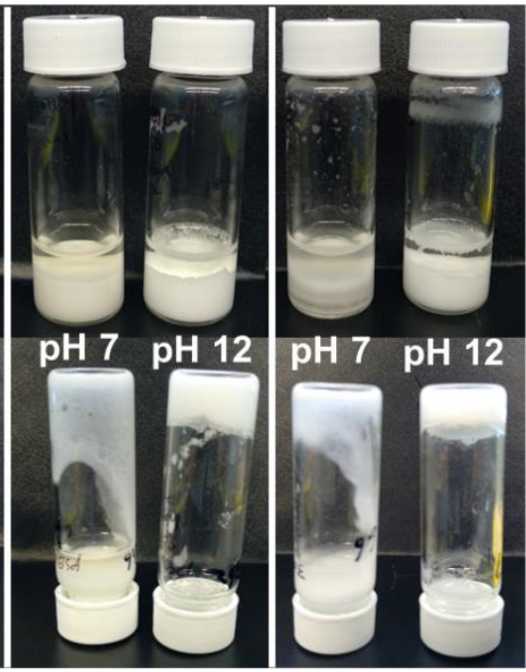

(c)

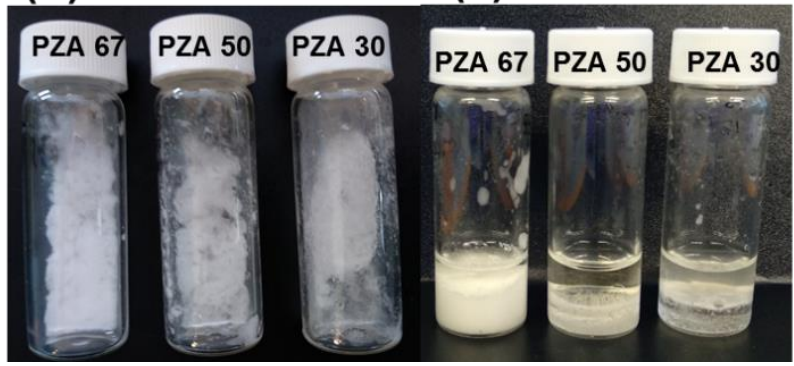

Figure S6. Photographs of oil-in-water emulsions prepared from PZA-67, 50 and 30. (a) Emulsions at pH 7 and 12; (b) non-sticky emulsions following addition of $\mathrm{NaOH}_{(\mathrm{aq})}$; (c) sticky emulsions following addition of $\mathrm{HCl}_{(\mathrm{aq})}$. [polymer] $=10 \mathrm{mg} / \mathrm{mL}$; oil $=\mathrm{TCB}$. 

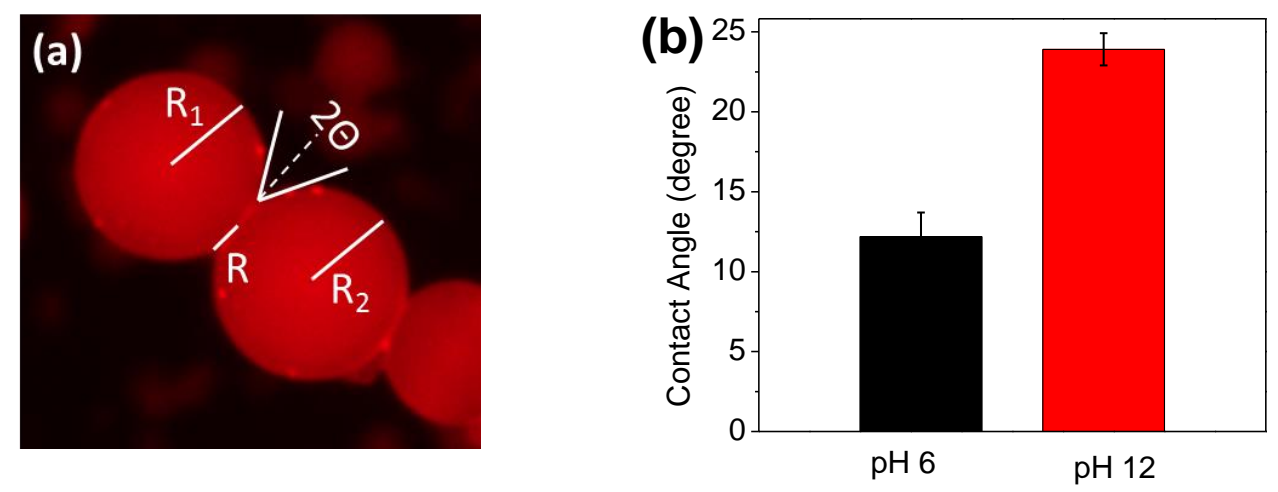

Figure S7. Inter-droplet contact angles $(\theta)$ at different $\mathrm{pH}$ values: (a) Fluorescence image of droplets stabilized by PZA-50 at pH 11.6; (b) at pH 6 and 12. [polymer] $=10 \mathrm{mg} / \mathrm{mL}$, oil TCB, $\Phi_{\text {oil }}=0.67,1 \mathrm{mg} / \mathrm{mL}$ Nile red in TCB. The contact angle and adhesion energy represent the average of 10 droplet pairs and the radius difference of the two droplets is less than $10 \%$ and contact angle is calculated by equation $2 \theta=\sin ^{-1}\left(R / R_{1}\right)+\sin ^{-1}\left(R / R_{2}\right)$.

Table S3. Interfacial tension $(\mathrm{mN} / \mathrm{m})$ of polymer-stabilized water-TCB interface

\begin{tabular}{ccccc}
\hline TCB-Water & PSBS & PZA67 & PZA50 & PZA30 \\
\hline 42 & 15 & $16(\mathrm{pH6} 8)$ & $19(\mathrm{pH} \mathrm{6.4)}$ & $18(\mathrm{pH} 6.6)$ \\
\cline { 2 - 4 } & & $10(\mathrm{pH} 9.8)$ & $3.6(\mathrm{pH} 9.6)$ & $2.5(\mathrm{pH} 9.7)$ \\
\hline
\end{tabular}




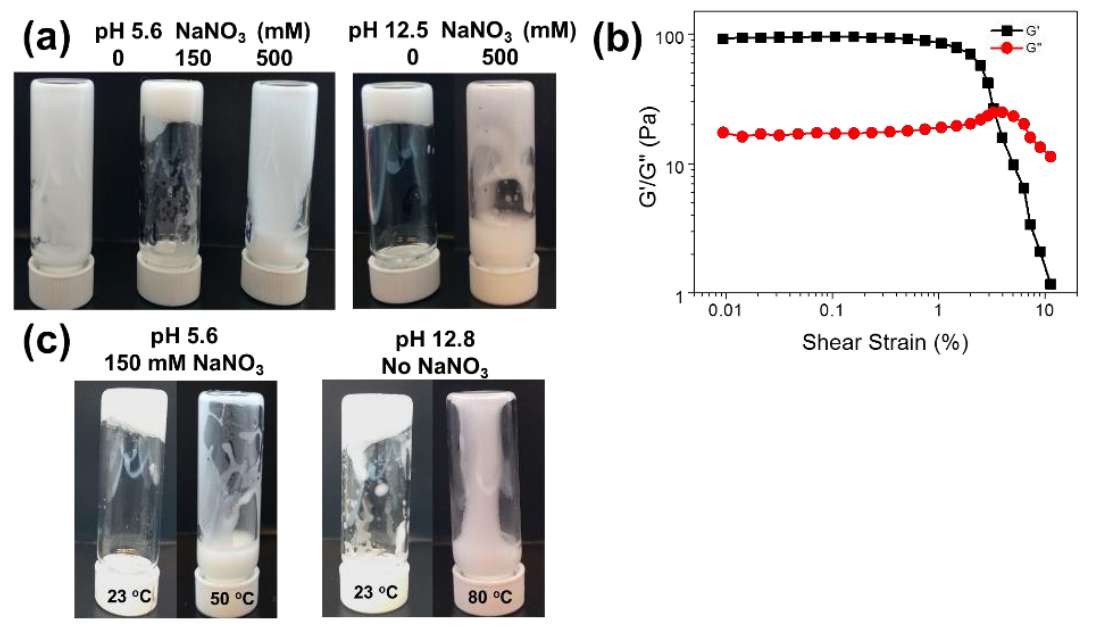

Figure S8. PZA-50 stabilized emulsions at different salt concentrations and temperatures: (a) photographs of emulsions at different $\mathrm{NaNO}_{3}$ concentration, (b) rheological properties of polymer at $\mathrm{pH} 6$ with $150 \mathrm{mM} \mathrm{NaNO}_{3}$ as a function of oscillatory shear stress and at a fixed frequency = $63 \mathrm{rad} \mathrm{s}^{-1}$ for a-c, [polymer] = $10 \mathrm{mg} / \mathrm{mL}$; oil = TCB; (c) photographs of emulsions at different temperatures. 

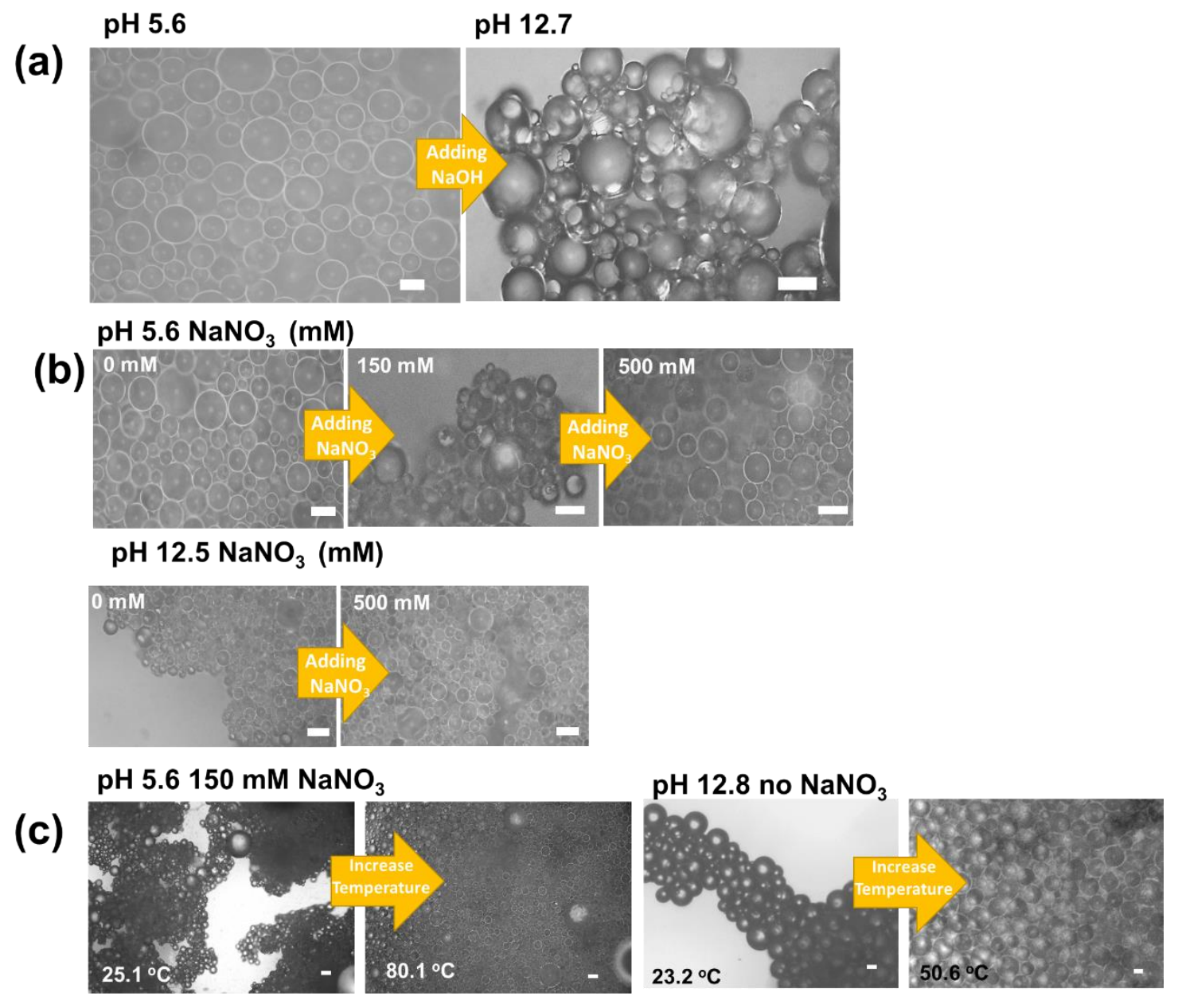

Figure S9. Optical micrographs of PZA-50-stabilized oil-in-water emulsions: (a) prepared at $\mathrm{pH}$ 5.6 and then increased to $\mathrm{pH}$ 12.7; (b) prepared at $\mathrm{pH} 5.6$ and 12.5 with increasing $\mathrm{NaNO}_{3}$ concentration; (c) prepared at $\mathrm{pH} 5.6$ in $150 \mathrm{mM} \mathrm{NaNO}_{3}$ and $\mathrm{pH} 12.8$, salt-free, with increasing temperature. For a-c, the scale bar is $100 \mu \mathrm{m}$, the [polymer] is $10 \mathrm{mg} / \mathrm{mL}$, and the oil is TCB. 


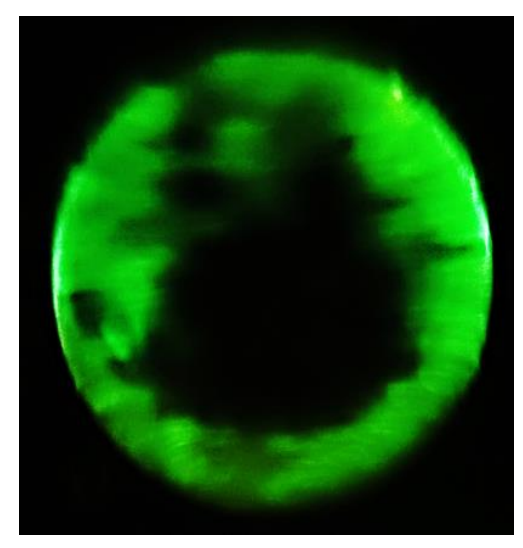

Figure S10. Fluorescence micrograph of an oil-in-water droplet resulting from coalescence of a supracolloidal fiber that was stabilized initially by PZA50-FITC. [polymer] $=10 \mathrm{mg} / \mathrm{mL}$; oil $=$ TCB. See Movie S1 for an example of triggered fiber collapse.

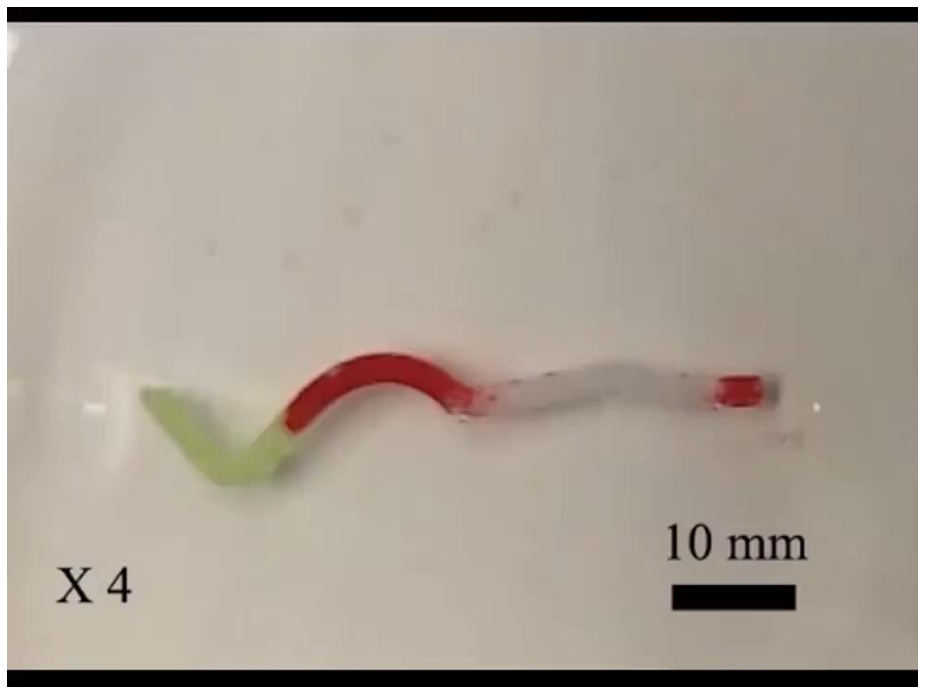

Movie S1. Acid-induced coalescence of a PZA-50-stabilized supracolloidal fiber in water. TCB is the oil phase, the yellow segement contains Coumarin 153, and the red segment contains 1 $\mathrm{mg} / \mathrm{mL}$ Dispersed Red 13. $1 \mathrm{M} \mathrm{HCl}$ was added to the yellow end of the fiber (on the left side). (double click on movie to activate). 


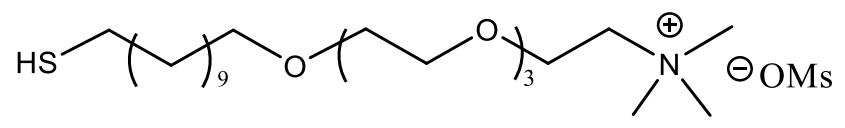

Figure S11. Structure of quaternary ammonium thiol linker used to functionalize Au patches on Si substrates.
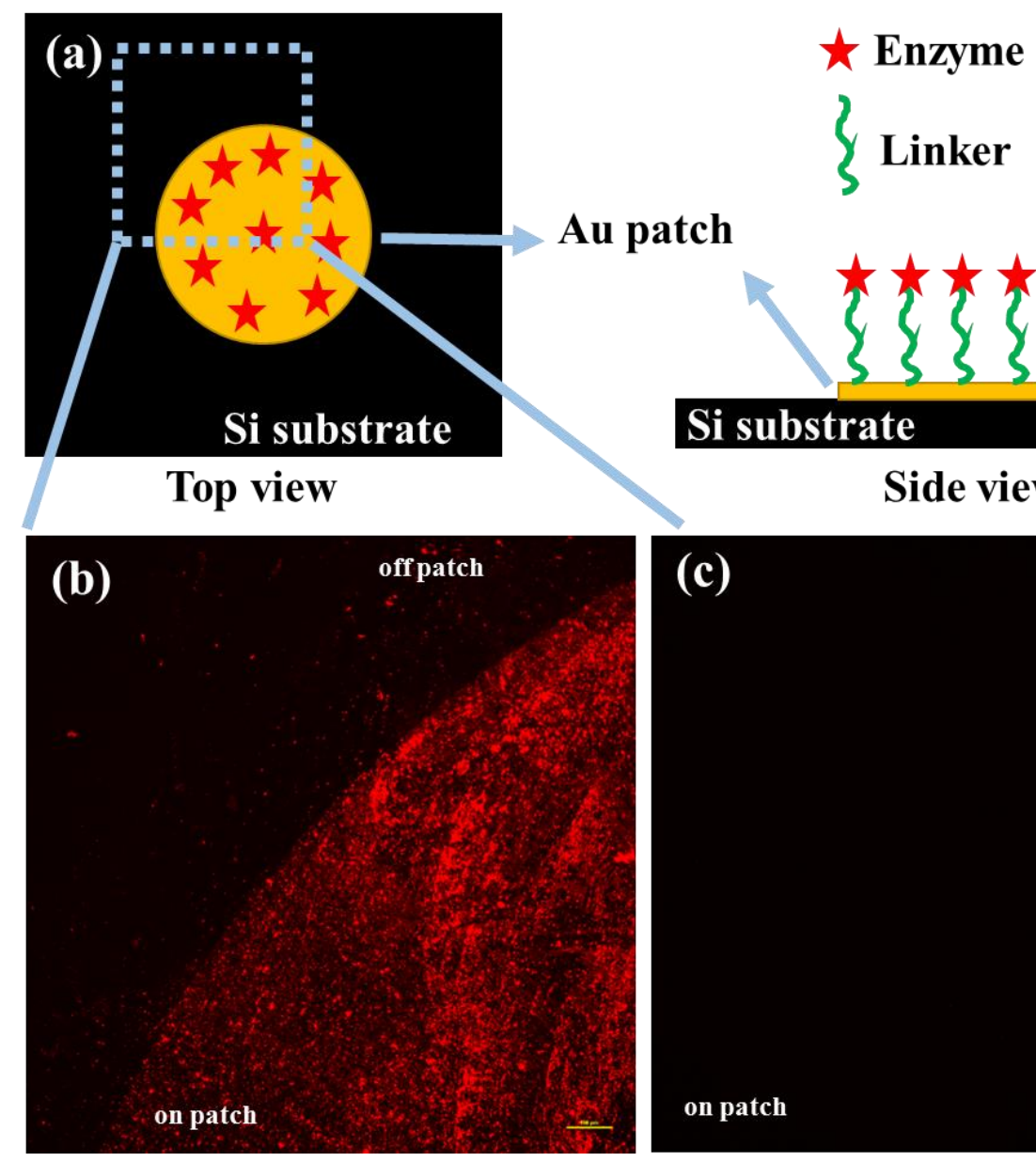

\section{Au patch}

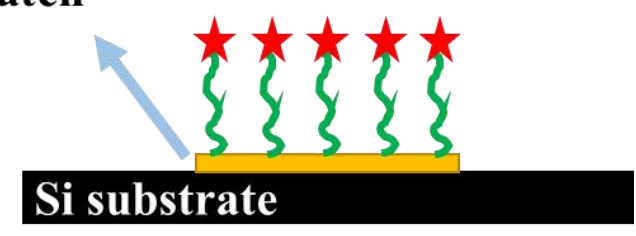

Side view

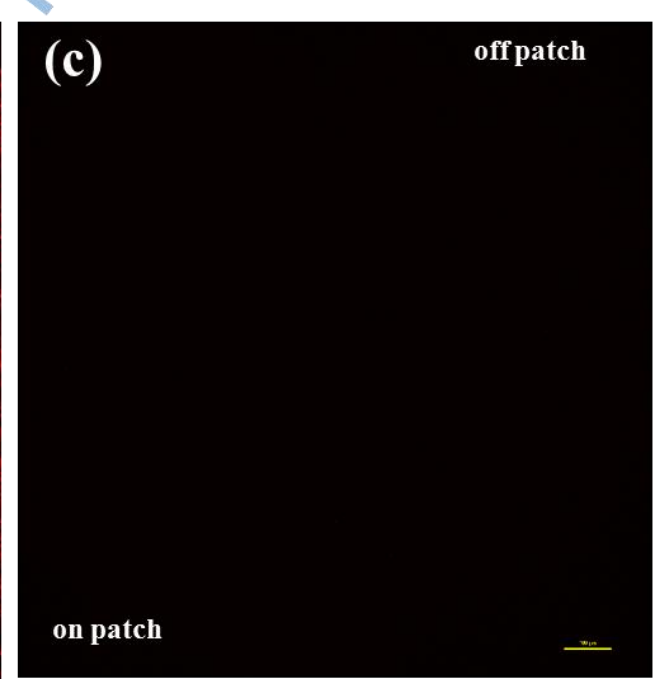

Figure S12. (a) Schematic of Au-patterned Si substrates after incubation with the fluorescent enzyme; $(b, c)$ red emission indicates areas of enzyme immobilization substrate which are dark in on substrates lacking the enzyme. Images were acquired using a Nikon TiE with N-STORM/TIRF microscope equipped with a $10 \mathrm{X}$ objective using excitation and emission filters on the range of 528-533 $\mathrm{nm}$ and 590-650 $\mathrm{nm}$, respectively. 

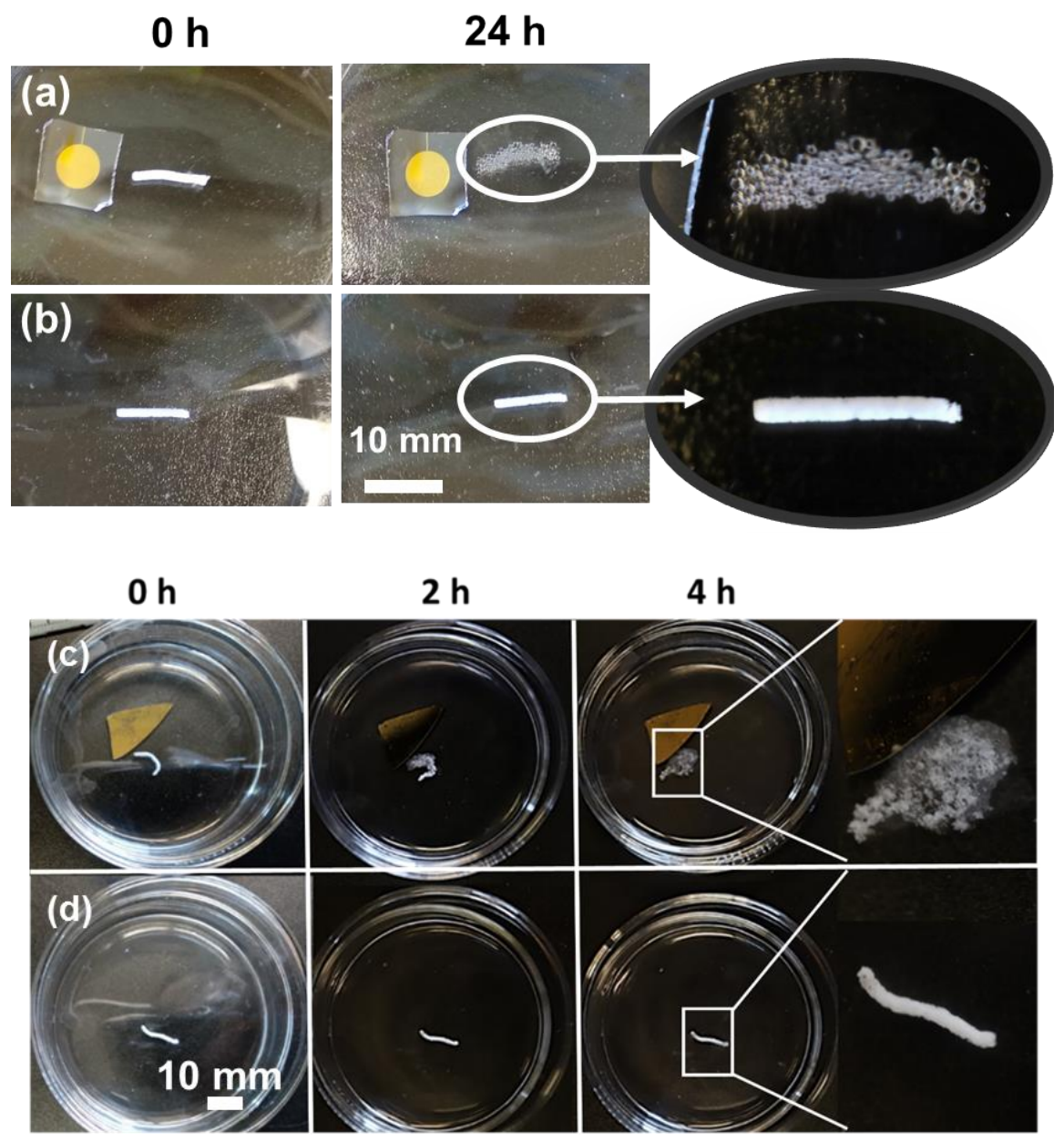

Figure S13. Photographs of supracolloidal fibers in a $20 \mathrm{mg} / \mathrm{mL}$ glucose solution at room temperature (a) with (b) without immobilized GOx on Au-coated Si; (c) with (d) without GOx immobilized on a Au-coated Si substrate. [PZA50] = $10 \mathrm{mg} / \mathrm{mL}$; oil = TCB; oil phase fraction $\left(\varphi_{\text {oil }}\right)=0.67(\mathrm{pH} \mathrm{12})$. 

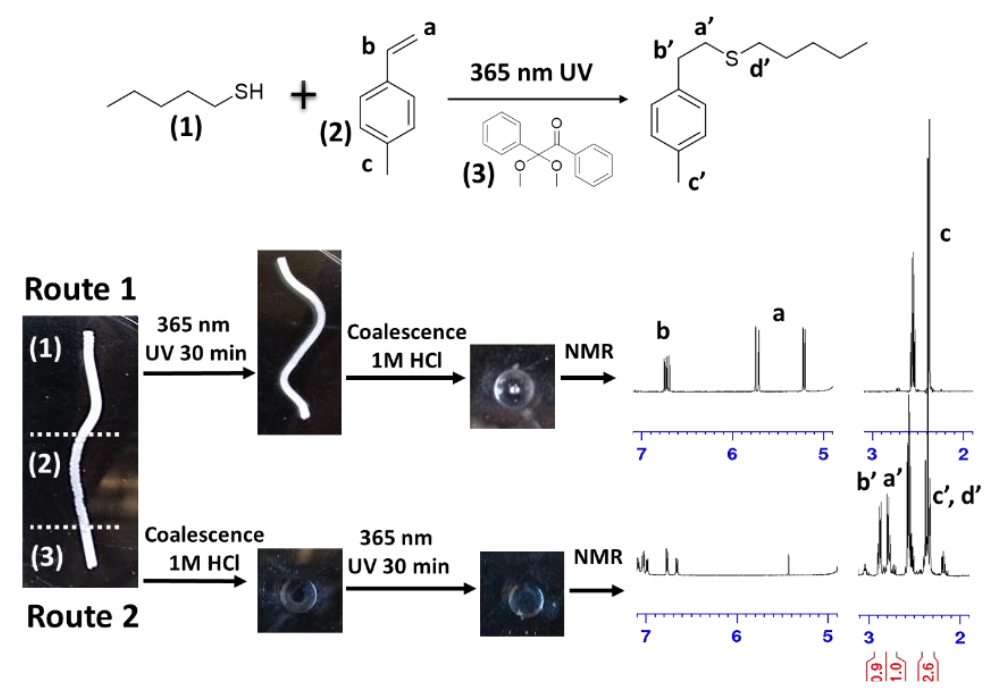

Figure S14. Thiol-ene addition in PZA-50-stabilized supracolloidal fiber. After the coalescenceinduced reaction, the ${ }^{1} \mathrm{H}$ NMR spectrum (bottom) indicates disappearance of characteristic 4methylstyrene signals and the appearance of product signals. The integration of a', b' and c'+d' (1:1:2.6) agrees with the expected 2:2:5 ratio. 


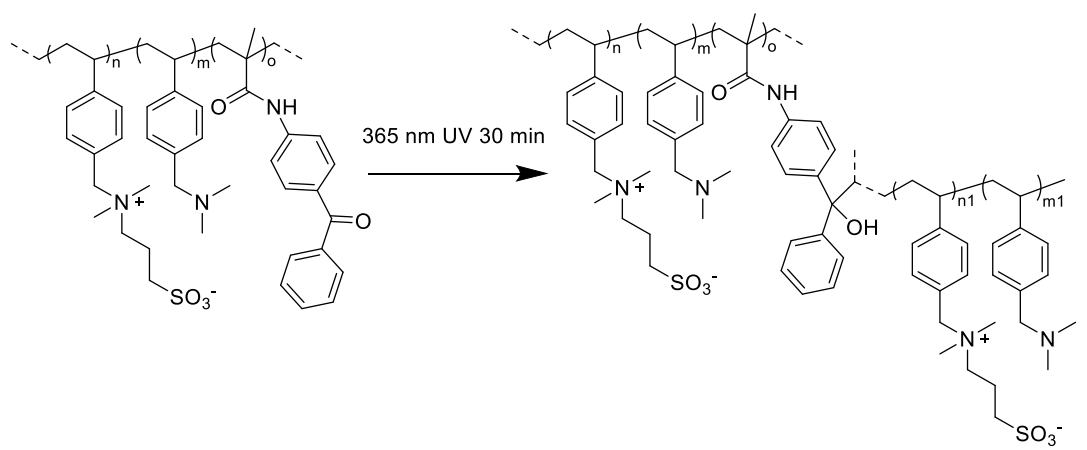

Figure S15. Polymer structure used in cross-linking of supracolloidal fibers. 
(a)

Origina
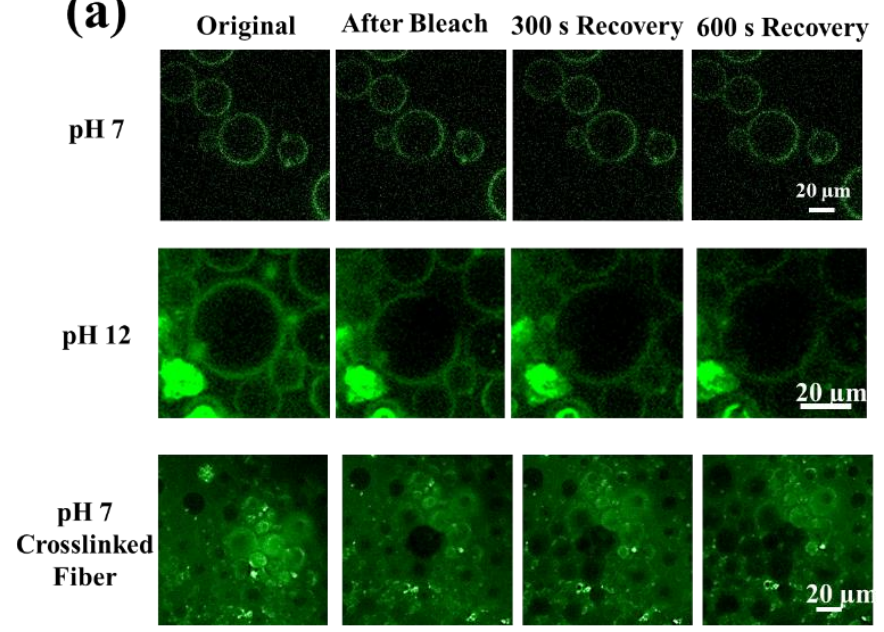

(b)

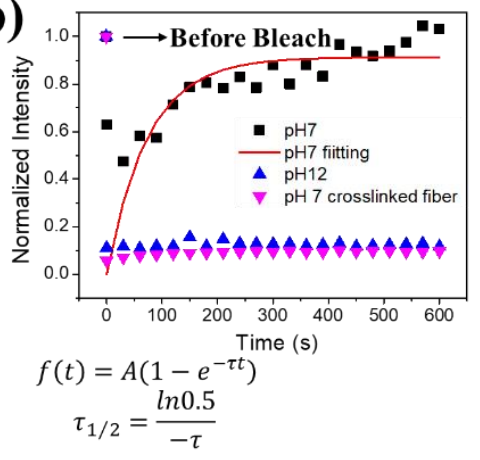

A: Mobile fraction $\tau_{1 / 2}$ : half life.

\begin{tabular}{ccc}
\hline $\mathrm{A}$ & $\tau$ & $\tau_{1 / 2}(\mathrm{~s})$ \\
\hline $\mathbf{0 . 9 1 2 8 0 8 0 . 0 1 3 5 1 5}$ & 51.3 \\
\hline
\end{tabular}

Figure S16. Fluorescence recovery after photobleaching (FRAP) experiments of (a) emulsion droplets stabilized by FITC-labeled PZA50 performed by fluorescence confocal microscopy (Zslice) with emission wavelength of $525 \mathrm{~nm}$, excitation wavelength of $488 \mathrm{~nm}$, and photobleaching wavelength of $408 \mathrm{~nm}$; (b) fluorescence recovery curves after photobleaching and corresponding curve fitting of emulsion droplet at $\mathrm{pH}$ 7. No fluorescence recovery is seen for the droplets at $\mathrm{pH}$ 12 (sticky droplets) and in the cross-linked fiber at $\mathrm{pH} 7$. 


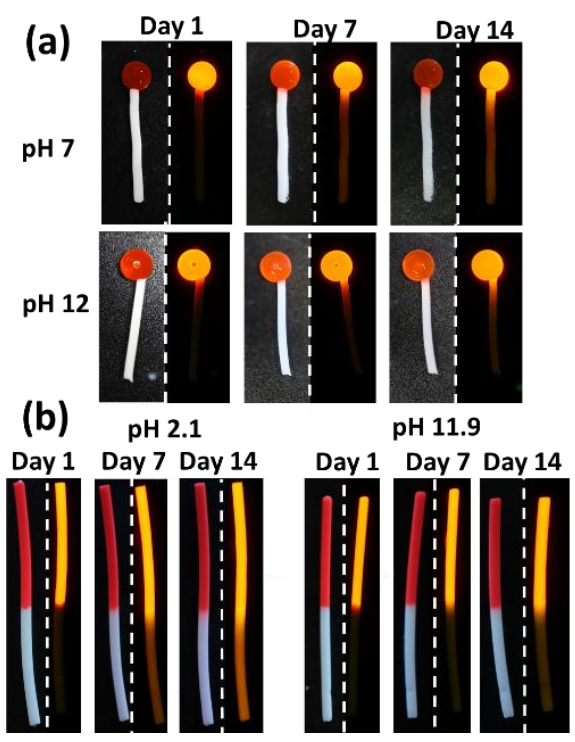

Figure S17. $\mathrm{pH}$-induced inter-droplet dye transport in PZA-50-stabilized fibers immersed in water, (a) uncrosslinked supracolloidal fibers at $\mathrm{pH} 7$ and 12 and (b) crosslinked two-segment fibers at pH 2 and 12. Photographs (left) and fluorescence images (right) for each pair of fibers. Conditions: [polymer] $=10 \mathrm{mg} / \mathrm{mL}$; oil $=$ TCB with $0.5 \mathrm{mg} / \mathrm{mL}$ Nile Red for (a) and (b). 


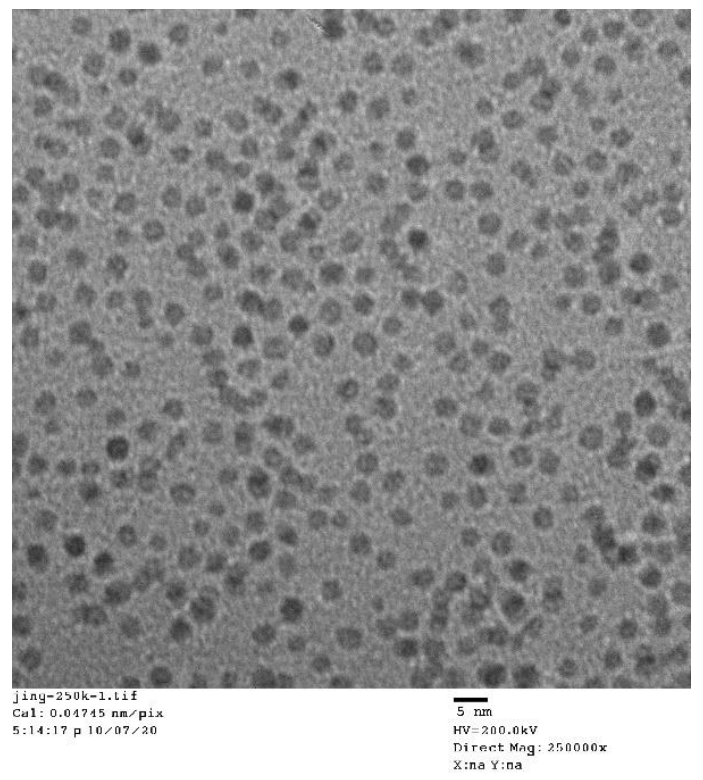

Figure S18. TEM image of Au NPs used for encapsulation in supracolloidal fibers (scale bar $=5$ $\mathrm{nm})$. 


\section{S.3 References}

1. C. F. S. Chalarca, T. Emrick, Reactive Polymer Zwitterions: Sulfonium Sulfonates. J. Polym. Sci. Pol. Chem. 2017, 55, 83-92.

2. J. Kim, J. A. Hanna, M. Byun, C. D. Santangelo, R. C. Hayward. Designing Responsive Buckled Surfaces by Halftone Gel Lithography. Science, 2012, 335, 1201-1205.

3. J. Zhao, M. A. Johnson, R. Fisher, N.A. D. Burke, H. D. H. Stöver, Synthetic Polyampholytes as Macromolecular Cryoprotective Agents. Langmuir 2019, 35, 1807-1817.

4. N. Zheng, J. Fan, G. D. Stucky One-Step One-Phase Synthesis of Monodisperse Noble-Metallic Nanoparticles and Their Colloidal Crystals. J. Am. Chem. Soc. 2006, 128, 6550-6551.

5. O. Miranda, H. Chen, C. You, D. Mortenson, X. Yang, U. Bunz, V. Rotello, Enzyme-Amplified Array Sensing of Proteins in Solution and in Biofluids. J. Am. Chem. Soc. 2010, 132, 5285-5289. 